Natriuretic peptides in the control of lipid metabolism and insulin sensitivity Peer-reviewed author version

VERBOVEN, Kenneth; HANSEN, Dominique; Jocken, Johan W.E. \& Blaak, Ellen E. (2017) Natriuretic peptides in the control of lipid metabolism and insulin sensitivity. In: Obesity Reviews, 18 (11), p.1243-1259.

DOI: $10.1111 /$ obr.12598

Handle: http://hdl.handle.net/1942/24857 


\section{Natriuretic peptides in the control of lipid metabolism} and insulin sensitivity

Kenneth Verboven $^{1,2}$, Dominique Hansen ${ }^{2,3}$, Johan W.E. Jocken ${ }^{1}$ and Ellen E. Blaak ${ }^{1}$

${ }^{1}$ Department of Human Biology, NUTRIM School of Nutrition and Translational Research in Metabolism, Maastricht University Medical Center+, Maastricht, The Netherlands

${ }^{2}$ REVAL - Rehabilitation Research Center, BIOMED - Biomedical Research Institute, Faculty of Medicine and Life Sciences, Hasselt University, Hasselt, Belgium

${ }^{3}$ Heart Centre Hasselt, Jessa Hospital, Hasselt, Belgium

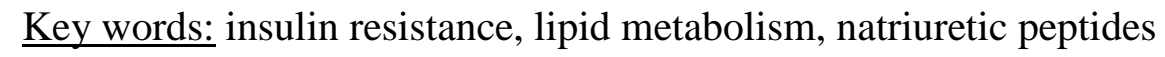

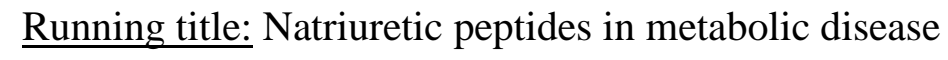

Acknowledgements/Funding:

The research in the authors' laboratories is funded by internal resources from Maastricht University and Hasselt University.

\section{Conflict of interest:}

None of the authors have any conflict of interest to declare.

Corresponding author:

Prof. dr. Ellen E. Blaak

Department of Human Biology, NUTRIM School of Nutrition and Translational Research in Metabolism, Maastricht University Medical Center + PO Box 616, 6200 MD, Maastricht, The Netherlands Phone: +31 433881503

Email: e.blaak@maastrichtuniversity.nl 
$\underline{\text { Abbreviations }}$

Insulin resistance, IR; type 2 diabetes mellitus, T2DM; fatty acid, FA; adipose tissue, AT; natriuretic peptides, NPs; atrial natriuretic peptide, ANP; B-type natriuretic peptide, BNP; Ctype natriuretic peptide, CNP; dendroaspis natriuretic peptide, DNP; glucagon-like peptide 1, GLP1; guanylyl cyclase, GC; natriuretic peptide receptor A, MAPK; mitogen-activated protein kinase, NPRA; natriuretic peptide receptor B, NPRB; cyclic GMP, cGMP; natriuretic peptide receptor C, NPRC; neutral endopeptidase, NEP; insulin-degrading enzyme, IDE; dipeptidyl peptidase-4, DPP4; body mass index, BMI; phosphatidylinositol 3-kinase, PI3K; protein kinase G, PKG; perilipin-1, PLIN-1; hormone sensitive lipase, HSL; adipose triglyceride lipase, ATGL; protein kinase A, PKA; cyclic AMP, cAMP; human ANP, hANP; phosphodiesterase 3B, PDE3B; tumor necrosis factor alpha, TNF- $\alpha$; brown adipose tissue, BAT; uncoupling protein 1, UCP-1; peroxisome proliferator-activated receptor gamma coactivator 1-alpha, PGC-1 $\alpha$; peroxisome proliferator activated receptor, PPAR; nonalcoholic fatty liver, NAFL; lipopolysaccharides, LPS.

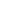

(1)

(1)

9

(1)




\section{Abstract}

Natriuretic peptides have long been known for their cardiovascular function. However, a growing body of evidence emphasizes the role of natriuretic peptides in human substrate and energy metabolism, thereby connecting the heart with several insulin sensitive organs like adipose tissue, skeletal muscle and liver. Obesity may be associated with an impaired regulation of the natriuretic peptide system, also indicated as a natriuretic handicap. Evidence points towards a contribution of this natriuretic handicap to the development of obesity, type 2 diabetes mellitus and cardiometabolic complications, although the causal relationship is not fully understood. Nevertheless, targeting the natriuretic peptide pathway may improve metabolic health in obesity and type 2 diabetes mellitus. This review will focus on current literature regarding the metabolic roles of natriuretic peptides with emphasis on lipid metabolism and insulin sensitivity. Furthermore, it will be discussed how exercise and lifestyle intervention may modulate the natriuretic peptide-related metabolic effects.

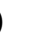

1




\section{Introduction}

Obesity is one of the major health problems of the twenty-first century as it is closely associated with the development of chronic metabolic diseases, including cardiovascular disease, insulin resistance (IR) and type 2 diabetes mellitus (T2DM) ${ }^{1-3}$. Different insulin sensitive organs tightly orchestrate energy and substrate metabolism in the human body. Therefore, alterations in these organs may contribute to the development of disturbances in fatty acid (FA) metabolism, ultimately leading to impaired glucose metabolism, IR and cardiometabolic disease. Next to the liver, skeletal muscle, the gastrointestinal tract and the pancreas, the adipose tissue (AT) is an important central organ in the inter-organ crosstalk in human energy and substrate metabolism. The AT is the primary site for long-term energy storage, mainly as triglycerides. However, a chronic excessive energy intake, like in obesity, results in enlargement (hypertrophy) of existing adipocytes. Since adipocytes have a limited expansion capacity, hypertrophy will lead to a reduced buffering capacity and dysfunctional AT may develop ${ }^{4,5}$. This AT dysfunction is further characterized by an altered lipid storage capacity and adipokine release, immune cell infiltration and low-grade inflammation, plays an important role in the development and/or progression of IR by promoting ectopic lipid storage and low-grade inflammation ${ }^{6-10}$. Physical activity intervention, whether or not combined with diet, may reduce the progression towards $\mathrm{T} 2 \mathrm{DM}^{11,12}$, possibly due to modulation of AT, liver and/or skeletal muscle FA metabolism ${ }^{10}$.

Only recently, research proposed natriuretic peptides (NPs) as important endocrine hormones implicated in the regulation of whole-body energy and substrate metabolism ${ }^{13-16}$. Atrial natriuretic peptide (ANP), B-type natriuretic peptide (BNP), both secreted by the heart, and C-type natriuretic peptide (CNP), mainly expressed by vascular endothelial cells and to a lower extent in cardiomyocytes ${ }^{17}$, are the three NP family members that may play a role in human substrate and energy metabolism. Besides their cardiovascular and renal effects 
110 (described extensively by Volpe et al. ${ }^{18}$ ), NPs play a role in different metabolic processes

111 including lipid mobilization in human white AT ${ }^{13,15}$, energy dissipation in brown AT,

112 browning of white AT ${ }^{19}$ and fat oxidation in human skeletal muscle ${ }^{20}$, possibly influencing

113 whole-body FA metabolism, glucose homeostasis and insulin sensitivity. In addition to their

114 wide range of metabolic effects in human insulin sensitive tissues, plasma NP levels were also

115 reported to be negatively associated with cardiometabolic diseases ${ }^{21-26}$ and have been even

116 suggested to have a predictive value in the development of new onset T2DM ${ }^{25}$. However, a

117 better understanding of the interaction between NPs and tissue energy, FA and glucose

118 metabolism is necessary to obtain a better insight in the role of NPs in the development of IR,

119 T2DM and cardiometabolic complications.

120 In this review, we will discuss the current knowledge regarding the role of NPs in the control 121 of human lipid metabolism and insulin sensitivity. At first, NP secretion, clearance and 122 signaling is discussed. Subsequently, the role of NPs in the etiology of obesity and T2DM is 123 discussed, as well as their effects on AT, skeletal muscle and liver metabolism. Moreover, the benefits of lifestyle and/or exercise interventions with respect to NPs in the control of insulin sensitivity are considered.

\section{Secretion and processing of NP}

127 The discovery of the endocrine properties of the heart by deBold in 1981, as shown by a

128 potent natriuretic and diuretic effect of atrial myocardial extracts in rats ${ }^{27}$, led to the reexamination of the function of the earlier discovered atrial myocardium granules ${ }^{28}$. The

130 dual nature of atrial cardiomyocytes (i.e. secretory-contractile function) became obvious and

131 research led to the identification of $\mathrm{ANP}^{29}$ and later the other NP-hormone family members

132 BNP, which is found at highest levels in cardiac ventricles, CNP, which is mainly expressed

133 in and produced by endothelial cells ${ }^{17}$. CNP, previously thought to act as a neuropeptide in 
134 the central nervous system ${ }^{30,31}$, is mainly viewed as a peptide regulating vascular blood 135 pressure ${ }^{32}$ and bone growth ${ }^{33}$, although a minor role in metabolic regulation has been 136 suggested ${ }^{34,35}$. In mammals, dendroaspis natriuretic peptide (DNP) (of which the synthesis

137 and secretion sites have not been identified) exerts renal actions via its specific receptor ${ }^{36}$ but 138 because it has not been well studied with respect to metabolic effects in humans, DNP will not 139 be further discussed in the current review.

140 Currently, ANP and BNP are the main metabolically active NPs described in literature and 141 will therefore be discussed in more detail in the present review. These peptides have a 17142 amino acid ring structure in common, formed by an intramolecular disulfide linkage, of which the sequence is highly preserved within the biologically active form of these peptides ${ }^{37}$.

144 Structural differences between NP family members are due to specific amino- and carboxy145 terminal extensions ${ }^{38}$. At rest, ANP (normal concentration range 5-50 pg/mL) is mainly 146 produced and secreted by the (right) atrial myocardium as a preprohormone ${ }^{39}$. The 147 intracellular granules of the atrial myocardium contain proANP which is cleaved by corin 148 (type II transmembrane serine protease expressed primarily in the heart) during secretion, resulting in a 28 -amino acid, bioactive $\alpha$ ANP peptide ${ }^{40}$, with a very short plasma half-life of about 2-4 $\min ^{41}$, and inactive fragments (N-terminal ANP and mid-regional-proANP) which have a longer plasma half-life (about $40-50 \mathrm{~min}$ ) ${ }^{41,42}$. BNP is mainly produced and secreted by the ventricular myocardium as preproBNP ${ }^{43}$. To become biologically active, preproBNP is cleaved to proBNP and subsequently, like for ANP, a cardiac protease, corin or furin, is responsible for the conversion to the 32-amino acid BNP (plasma concentration range 0-65 $\mathrm{pg} / \mathrm{mL}$ ) which is secreted in the circulation having a plasma half-life of about $15-25 \mathrm{~min}^{44}$, and the inactive $\mathrm{N}$-terminal fragment proBNP ${ }^{45}$. The latter inactive fragment has a plasma

157 half-life of about $60-120 \mathrm{~min}$ and a plasma concentration in the range of $7-220 \mathrm{pmol} / \mathrm{L}$ in 158 healthy individuals ${ }^{41}$. While the structure of BNP varies distinctly among species, ANP is 
159 strongly homologous between human and rodent ${ }^{45}$. The post-translational processing, 160 cleavage and degradation sites of NPs were recently reviewed by Volpe et al. ${ }^{18}$.

\section{Determinants of NP secretion}

Mechanical stretch of cardiomyocytes is the most important trigger for NP release in the circulation ${ }^{45}$. Atrial wall stretching causes an increase in ANP gene transcription and increased release of stored granules ${ }^{46}$. Ventricular wall stress, in case of volume or pressure overload, is mainly responsible for BNP transcription and secretion ${ }^{38}$. In addition, hypoxic conditions or myocardial ischemia are potent inducers of ANP secretion due to the presence of hypoxia-responsive elements in the promotor region of the ANP gene ${ }^{47}$.

Another potent stimulus for NP secretion is cold exposure. Animals and humans exposed to cold display a greater expression of ANP (mRNA) and BNP (mRNA and protein) in the heart, combined with higher plasma levels, in conjunction with an elevated sympathetic nervous system activation in the heart ${ }^{19}$. Cold-induced elevation of NPs levels might result from increased blood pressure in response to skin vasoconstriction and altered central blood volumes, thereby augmenting cardiac filling pressure and thus NPs'secretion ${ }^{48,49}$.

Besides mechanical stretch and cold exposure, endocrine regulation of NP secretion is present as well. Sex steroids, thyroid hormones, glucocorticoids, endothelin-1, angiotensin II and inflammatory cytokines (tumor necrosis factor- $\alpha$, interleukin-1 and -6) all are able to modulate NP secretion ${ }^{38,45,50}$. Inflammatory cytokines stimulate BNP transcription and translation in vitro in murine cardiomyocyte cultures ${ }^{51}$ and in vivo secretion into the plasma in human transplant patients specifically ${ }^{52}$. In this regard, it was shown that the glucagon-like peptide 1 (GLP1) receptor agonist liraglutide was able to induce a significant increase in ANP secretion in mice due to the presence of GLP1 receptors on right atrial cardiomyocytes ${ }^{53}$. However, the existence of a GLP-1-ANP axis could not be confirmed in men or patients with 
$\mathrm{T}^{2} \mathrm{DM}^{54-57}$. ANP and BNP plasma levels also increase with age, possibly due to an agerelated reduction in coronary blood flow reserve and thus increased myocardial ischemia ${ }^{58-60}$. Modulation by sex steroids may result in sex dependent regulation of NP levels ${ }^{60-62}$. An effect of sex hormones during adolescence was already observed in pubertal versus postpubertal adolescents, where NP concentrations are lower in post-pubertal boys compared with pubertal boys ${ }^{63}$. Estrogens might have a stimulatory effect on the production and secretion of ANP and BNP by the cardiomyocyte, whereas androgens may have an inhibitory effect ${ }^{61}$. In part, the increased NP levels in women might have clinical implications for sex-related difference in relative risk of developing metabolic and cardiovascular disease. Furthermore, during adolescence NPs levels seem to increase progressively in girls ${ }^{58,59}$, probably the result of an interaction between the increased estrogen concentration and ANP transcription and secretion or via the regulation of the NPs receptor expression ${ }^{64}$. Plasma CNP levels alternatively decrease during adolescence until the age of fifty, whereupon they tend to increase. CNP concentrations are higher in men than in women as testosterone and growth hormone are able to induce $\mathrm{CNP}^{65}$.

Finally, metabolically compromised conditions like obesity, insulin resistance and T2DM may be characterized by altered systemic NP concentrations, which will be discussed more extensively later in this review.

\section{NP receptors and signaling}

To exert their main biological effects NPs bind to NP receptors, of which three subtypes have been described (reviewed recently by Kuhn) ${ }^{66}$. ANP and BNP bind with a high affinity to a membrane-bound receptor, containing a transmembrane segment, with specific guanylyl cyclase (GC) activity called NP receptor A (NPRA). CNP is mainly bound to NP receptor B $(\mathrm{NPRB}){ }^{67}$, similar in structure and function to NPRA and mainly expressed by chondrocytes, 
thereby playing a role in long bone growth ${ }^{68}$. Ligand binding to a NPRA homodimer results

208 in the internalization of the bound ligand-receptor complex and the activation of cytosolic

209 GC, the catalytic effector of the receptor, subsequently causing hydrolysis of GTP into cyclic GMP (cGMP). This second messenger is able to activate various biological responses via cGMP-dependent protein kinases, cGMP-gated ion channels or other effector proteins ${ }^{69}$. A

212 large proportion of the ligand-bound receptor undergo lysosomal degradation, in which about $75 \%$ of the internalized ANP is processed in the lysosomes and $25 \%$ is released as intact molecules through a recycling pathway. A small amount of internalized receptors is recycled back to the plasma membrane or released into the cell exterior ${ }^{70}$. The NP receptor C (NPRC) is the third subtype, having an extracellular domain that is partly homologous to those of

217 NPRA receptors and thus has the ability to bind NPs, with the highest affinity to ANP and

218 lowest to BNP ${ }^{71}$. However, NPRC lacks GC activity and instead its main function is to facilitate scavenging of its ligands, internalization of ligand-receptor complexes and recycling of NPRC, together with lysosomal degradation of its ligands ${ }^{72,73}$. Besides via lysosomal clearance, NPs can be degraded intracellularly by endopeptidases including neutral endopeptidase (NEP) ${ }^{74}$, which is also produced in adipocytes ${ }^{75}$. In addition, insulindegrading enzyme (IDE) enzymatically cleaves NP ${ }^{45,76}$ and dipeptidyl peptidase-4 (DPP4 or CD26) cleaves the N-terminal peptide of NPs thereby lowering biological activity ${ }^{77}$. Another route to clear circulating NP is via secretion into body fluids like urine (via glomerular filtration) and bile ${ }^{45}$.

The main effector receptor for ANP and BNP, NPRA, is highly expressed throughout the cardiovascular system (vascular smooth muscle and endothelial cells with only a limited expression in the heart), in kidney and adrenal gland, as well as in different metabolic organs like skeletal muscle, pancreas, liver, brain, gut and AT ${ }^{37,78,79}$. Expression of the scavenging NPRC, the most widely expressed NPs receptor, is mainly present in the AT, kidneys, lungs, 
232 the cardiovascular system and blood monocytes ${ }^{73,80,81}$. Interestingly, NPRA and NPRC

233 display diurnal regulations (in antiphase of one other) in the rodent white AT ${ }^{82}$, not in the

234 heart muscle ${ }^{83}$, which together with the circadian regulated plasma NPs ${ }^{84,85}$, may be a

235 characteristic for energy homeostasis during the day. Furthermore, the local tissue specific

236 and systemic effects of NP are thought to depend on the ratio between NPRA and NPRC ${ }^{86,87}$.

237 Collectively, NPs mediate their effects via NP receptors, of which three subtypes have been

238 described. The diverse effects of NPs, systemically as well as the local tissue effects, are

239 determined by NP receptor expression profiles and their ligand-affinity.

\section{Systemic NP deficiency in obesity, insulin resistance and type 2 diabetes mellitus}

Evidence from several epidemiological studies demonstrated an inverse association between systemic NPs levels (both ANP and BNP) and body weight (mostly expressed by body mass index (BMI) ${ }^{21,23,88-92}$. The inverse relationship between NP levels and BMI was also found in

244 the presence of left ventricular hypertrophy ${ }^{93}$. However, these studies lack detailed body composition analyses thereby not being able to differentiate between fat accumulation or fluid retention as a cause of the increased BMI. In contrast, other smaller cohorts showed that there is no or even a positive relationship between circulating NPs levels and BMI ${ }^{94,95}$.

248 Furthermore, NPs may affect AT distribution ${ }^{96,97}$. Variations in regional and particularly 249 visceral adiposity were strongly related to circulating N-terminal-pro-BNP. The relationship 250 of NPs with subcutaneous adiposity was less strong ${ }^{97}$. This relation could be partly 251 moderated by the hyperinsulinemic state that is frequently observed in visceral adiposity, as 252 high insulin levels have been shown to suppress NPs secretion and activity ${ }^{98,99}$. The Dallas

253 Heart Study recently showed that both BNP and N-terminal-proBNP are inversely related to 254 visceral and liver fat, while being positively associated with gluteofemoral body fat, 255 independent of insulin sensitivity ${ }^{100}$. 
Of interest, it is important to take into account obesity comorbidities including the presence of

257 cardiac burden in considering these results ${ }^{101}$. The decrease in systemic NPs levels may be accompanied by higher blood aldosterone concentrations, as a consequence of an impaired NPs-mediated renin-angiotensin-aldosteron system inhibition ${ }^{102,103}$, thereby leading to obesity-related hypertension ${ }^{22}$ or an increased incidence of all-cause mortality ${ }^{91}$. The substantial role of NPs deficiency in the pathogenesis of obesity-related hypertension was recently corroborated in healthy obese men, showing a negative association between serum mid-regional-proANP and mean 24-hour systolic ambulatory blood pressure ${ }^{104}$. Moreover, research indicated that NPs deficiency might enhance cardiovascular risk ${ }^{18}$. Although not all mechanisms involved in obesity-related hypertension are well understood ${ }^{105}$, NPs might partially link obesity and metabolic syndrome to hypertension ${ }^{106}$.

As obesity is often associated with IR or T2DM, a link between the NPs system, obesity and T2DM seems plausible. Recent research indicated that NPs deficiency might increase the risk of T2DM onset ${ }^{107}$. Indeed, two recent prospective cohort studies showed evidence supporting this hypothesis ${ }^{25,26}$. Results of the Malmö Diet and Cancer Study showed mid-regionalproANP plasma levels to be inversely associated with new-onset diabetes development (i.e, diabetes incidence) and an impaired glucose metabolism over the 16-year follow-up period of the study, which was also true for N-terminal-proBNP plasma levels, although not statistically significant ${ }^{25}$. In this regard, mid-regional-proANP is believed to be a better predictor of T2DM incidence compared to $\mathrm{N}$-terminal-proBNP ${ }^{25}$, the latter being more sensitive to mild forms of left ventricular dysfunction ${ }^{108}$ which is relatively frequent (even subclinically) in the obese state ${ }^{109}$. Circulating ANP (measured as mid-regional-proANP) within the normal high range ( 212-372 pg/mL) was associated with lower risk of IR during a 16-year follow-up period in a middle-aged cohort ${ }^{110}$. This association was independent of diabetes risk factors (including waist circumference, plasma levels of triglycerides, HDL-cholesterol, systolic 
blood pressure, antihypertensive treatment, age and sex) or renal function (cystatin C) ${ }^{25}$. In

282 the Atherosclerosis Risk in Communities Study (a community-based population study), it was

283 shown that having low N-terminal-proBNP levels (lowest quartile, $<31 \mathrm{pg} / \mathrm{mL}$ ) was associated

284 with higher risk of incident diabetes over a 12 year follow-up period in subjects without

285 T2DM at baseline. These results were consistent across race, gender and BMI categories ${ }^{26}$,

286 and were independent of age ${ }^{111,112}$. Of interest, statistical adjustment for BMI did not

287 abrogate the association between low NP levels and diabetes onset ${ }^{113}$. These results are in

288 line with the Framingham Heart Study and the Malmö Diet and Cancer Study, which showed

289 that lower N-terminal-proBNP levels were associated with higher incidence of IR in lean as

290 well as in obese subjects in a cross-sectional study ${ }^{23}$. Additionally, prospective cohort data

291 from the Women's Health Study showed that subjects with N-terminal-proBNP levels near

292 the upper limit of the normal range $(>117 \mathrm{pg} / \mathrm{mL})$ have a significantly lower risk of

293 developing diabetes ${ }^{114}$.

294 Thus, there is consistent evidence that increased NP concentrations are protective against IR

295 and T2DM ${ }^{114-116}$. In line, lower blood glucose concentrations were transiently observed upon

296 systemic BNP infusion during intravenous glucose tolerance testing in young, healthy lean

297 men with normal glucose tolerance ${ }^{117}$. Moreover, in a random subset of a general middle-

298 aged population (age $>45$ years) a genetic variant of the ANP gene (single nucleotide

299 polymorphism rs5068) was associated with higher N-terminal-proANP levels and a beneficial

300 cardiometabolic profile (i.e. reduced systemic blood pressure, BMI, waist circumference and a

301 lower risk of metabolic syndrome) compared to the A/A carriers ${ }^{89}$. This ANP gene-

302 polymorphism was accompanied with a lower incidence of T2DM after a 14-year follow-up

$303{ }^{118}$. Similarly, a genetic polymorphism in the promotor region of the BNP gene (T-381C

304 polymorphism) is associated with higher plasma BNP levels and lower risk of T2DM in 
several population samples including individuals with normoglycemia, impaired glucose tolerance and $\mathrm{T} 2 \mathrm{DM}{ }^{119}$.

Altogether, the presence of a NPs deficiency in metabolic disease is generally accepted, as acknowledged by large (but challenged by some smaller) cohorts, but the cause remains incompletely understood. Nonetheless, it is imperative to understand the etiology of this anomaly to further establish the clinical relevance of using mid-regional-ANP and/or Nterminal-proBNP as biomarkers for diabetes prediction ${ }^{15}$.

\section{Underlying mechanism for systemic NP deficiency in obesity}

Several potential explanations for the observed systemic NPs deficiency in human obesity, and more general human metabolic disease, have been proposed, apart from common variants of the human ANP and BNP genes that affect circulating NP concentrations ${ }^{114,116,120}$. One explanation could be that the NP deficiency may be due to an increased NP degradation in human AT of obese ${ }^{78,71,86}$ and obese hypertensive individuals ${ }^{22}$, which is mainly fulfilled by NPRC-mediated lysosomal breakdown as mentioned before ${ }^{74,121}$. In addition, hyperinsulinemia increased NPRC expression in vitro in 3T3-L1 adipocytes ${ }^{86}$, human adipocytes ${ }^{86,122}$ and in human subcutaneous AT of healthy, moderately obese individuals with normal glucose tolerance during hyperinsulinemic-euglycemic and hyperinsulinemichyperglycemic clamps ${ }^{81}$, mainly through the phosphatidylinositol 3-kinase (PI3K) pathway ${ }^{86}$. Moreover, previous work of Sarzani et al. ${ }^{96}$ with a genetic NPRC variant shows that a reduced NPs clearance (or resulting increased systemic levels) might be associated with a reduced content of upper body fat and a lower risk of developing abdominal obesity. Together, these data suggest that the AT may be responsible for the increased NP clearance and lowering systemic NP availability in obese insulin resistant conditions ${ }^{81,123}$. 
However, results from the Dallas Heart Study showed that the association between BMI and circulating NP levels is explained by the amount of lean mass, and not AT mass, indicating that lean tissue could also be important for plasma NP regulation ${ }^{88}$. Indeed, upregulation of NPRC in human skeletal muscle tissue, next to down-regulation of the NPRA expression in the AT and skeletal muscle of obese and/or obese diabetic humans and mice has been found ${ }^{124,125}$. Thus, besides AT, also skeletal muscle may contribute to the NP deficiency observed in T2DM in the long-term, certainly considering that muscle mass accounts for up to $40 \%$ of total body weight. Therefore, even a moderate increase in skeletal muscle NPRC expression could markedly reduce NPs plasma levels ${ }^{124}$.

Additionally, it has been shown that NPRC mRNA expression is down-regulated in vitro following starvation in human differentiated adipocytes ${ }^{122}$ and in vivo in rat white and brown AT ${ }^{126}$ while the opposite was true under high fat feeding in wild-type mice skeletal muscle, white and brown AT ${ }^{127}$. Like NPRC, NEP expression is increased in the plasma (protein) and AT (mRNA) of obese subjects, although there is no direct evidence for an increased NEP activity in human obesity ${ }^{128}$. Together, these findings propose an altered NPs receptor ratio in obese insulin resistant or T2DM individuals mainly due to an increased expression of adipose NPRC and NEP, possibly leading to elevated NP clearance.

On the other hand, a decreased cardiac ANP and BNP release in metabolic disease has also been proposed. Not only circulating NPs levels but also the side products of NPs release (Nterminal-proANP and N-terminal-proBNP) are reduced in obesity. These proteins are structurally distinct and are biologically inactive compounds, which makes NPRC mediated clearance of these components rather unlikely ${ }^{88,129}$. Of interest, NPs levels in the aortic root and the coronary sinus were observed to be negatively correlated with BMI ${ }^{130}$. These findings suggest that besides an increased clearance, a reduced cardiac NPs release might potentially contribute to the systemic NPs deficiency in metabolic diseases as well. This hypothesis was 
353 further acknowledged by the notion that cardiac ANP and BNP mRNA expressions were

354 reduced in obese Zucker fatty rats and $d b / d b$ mice ${ }^{131,132}$. Putative impairments in cardiac NPs

355 secretion in human metabolically compromised conditions needs to be explored further.

\section{NPs and their role in inter-organ crosstalk}

357 NPs are long known for their cardiovascular and renal actions ${ }^{18}$ resulting in the use of NPs 358 (or their fragments) as cardiovascular biomarkers in the clinic ${ }^{133}$. Over the last two decades, 359 pioneering studies by the group of Lafontan et al. suggested a protective role for the heart in 360 metabolic diseases ${ }^{134}$. The inter-organ crosstalk effectuated by ANP and BNP integrates 361 effects on AT function, skeletal muscle, liver, gut, central nervous system and pancreas, as 362 indicated in Figure 1.

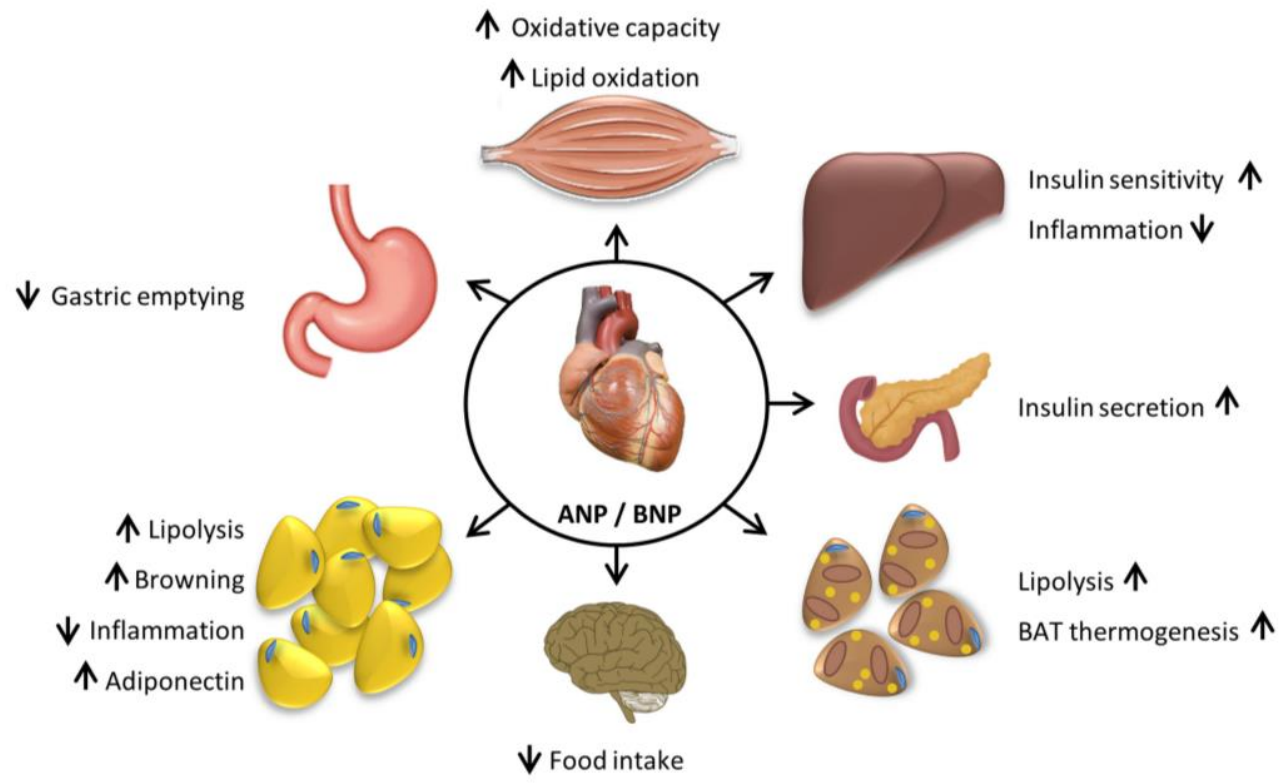

Figure 1 - Overview of the multiple metabolic actions of natriuretic peptides in the control of lipid metabolism and insulin sensitivity. 
As the human white AT is one of the main sites of NP receptor expression, investigating the effects of NPs on AT function seems obvious, in particular in the obese state. Next, the effects on AT lipolysis, brown AT metabolism (Table 1) and the role of NP in AT lipid metabolism in obesity and T2DM will be discussed in more detail.

\subsubsection{NP and adipose tissue lipolysis}

The potency of inducing a lipolytic effect by NPs was first described in isolated human adipocytes, with ANP being the most potent activator of lipolysis as compared to BNP and $\mathrm{CNP}$, the latter only showing a minor maximal lipolytic response (17\% as compared to maximal stimulation with isoproterenol) ${ }^{134}$. In addition, these lipolytic properties seem to be primate-specific, which may be due to the differential NPRC clearance receptor expression profiles in other mammalian adipocytes, especially in rodents, making ANP-mediated lipolysis less likely ${ }^{135}$. The signaling pathway relies on cGMP-dependent activation of protein kinase $\mathrm{G}(\mathrm{PKG})$, thereby promoting phosphorylation of perilipin-1 (PLIN-1) and

382 hormone sensitive lipase (HSL) to trigger triglyceride hydrolysis ${ }^{134,136,137}$, in which adipose triglyceride lipase (ATGL) might be involved as well ${ }^{122}$, the latter probably via a different signaling pathway (i.e. AMP-activated kinase) ${ }^{138}$ as compared with HSL activation (i.e. protein kinase A (PKA) and PKG) ${ }^{139}$. NPs-induced lipolysis is completely independent from the catecholamine-induced (cyclic AMP (cAMP)/PKA mediated) lipolysis, as they rely on different pathways ${ }^{140,141}$. However, an additive lipolytic effect occurs when human adipocytes are stimulated with ANP and a beta-adrenergic agonist (e.g. isoproterenol) simultaneously ${ }^{142}$. Infusion studies of human ANP (hANP), either intravenous or in situ through microdialysis in the subcutaneous AT, showed promotion of lipid mobilization in

391 healthy subjects, also in the presence of local beta-adrenergic blockade ${ }^{140}$. Infusing 
intravenous hANP (doses from $6.25-25 \mathrm{ng}^{*} \mathrm{~kg}^{-1} \mathrm{~min}^{-1}$ ), corresponding to the physiological

393 range observed during moderate exercise, stimulates whole-body lipid mobilization and

oxidation (in a dose dependent way), even in the postprandial state ${ }^{137,141,143}$. Furthermore, exercise-induced increases in systemic ANP concentrations (which may vary depending on the exercise/subjects' characteristics) lead to an increase in lipid mobilization, at least in lean healthy subjects ${ }^{144}$. In human obesity, lipolytic catecholamine-resistance is most commonly observed in the subcutaneous AT in the obese insulin resistant state ${ }^{145-147}$. Additionally, an impaired ANP-mediated lipolysis has been reported in vitro and in situ in human subcutaneous AT of patients with obesity and/or type 2 diabetes and overweight men compared to non-obese counterparts ${ }^{125,148}$. Of interest, ANP-mediated lipid mobilization was reported to be higher in subcutaneous compared to visceral adipocytes of lean individuals ${ }^{148}$, a difference that was not present in individuals with obesity ${ }^{148,149}$. The blunted ANPmediated lipolysis in the subcutaneous AT of obese insulin resistant individuals may be in part due to an up-regulation of NPRC and a down-regulation of NPRA mRNA and protein in human subcutaneous adipocytes ${ }^{125,148}$.

An interaction between the NPs' system and the anti-lipolytic hormone insulin was first suggested by Endre et al. ${ }^{150}$, who showed that hyperinsulinemic euglycemic clamping caused a decrease in serum ANP in normotensive and hypertensive men. This finding was confirmed in obese men ${ }^{81}$ but not in young lean individuals ${ }^{151}$. Insulin inhibits the catecholamineinduced lipolysis via activation of phosphodiesterase 3B (PDE3B), but does not have a direct anti-lipolytic effect on the ANP-mediated lipolytic pathway ${ }^{152}$. However, insulin might attenuate ANP-mediated lipolysis by inducing NPRC expression, as described earlier in this review. Of interest, the presence of low-glucose conditions together with insulin stimulation abolished NPRC expression to basal levels, indicating the existence of a "nutritional signaling" in NPRC regulation ${ }^{122}$. The relative ratio of NPRA to NPRC mRNA levels in 
417 subcutaneous AT was decreased depending on glucometabolic status since patients with

418 T2DM had the lowest ratio compared to subjects with normal glucose tolerance or impaired

419 glucose metabolism ${ }^{148,153}$.. Acute increases in systemic blood glucose decreased circulating

420 N-terminal-proANP in lean, overweight and obese subjects, a mechanism mediated through

421 glucose-induced miR-425 expression ${ }^{154}$, a negative regulator of NPRA ${ }^{155}$. Insulin thus seems

422 to be a key hormone in the connection between glucose/lipid metabolism and NPs' metabolic

423 activities.

424 Together, these findings indicate that augmenting ANP-mediated lipolysis, possibly by 425 improving insulin sensitivity, might be a target to improve lipid turnover in the obese insulin 426 resistant and/or T2DM state.

\subsubsection{NP and adipokines}

Another way to link NPs to AT function is the ability of NPs to alter expression and secretion of adiponectin, an adipokine with insulin sensitizing properties, both in vitro ${ }^{156}$ and in vivo ${ }^{157}$ in healthy subjects. Moreover, adiponectin is positively associated with NPs $100,111,158,159$. Other insulin desensitizing mediators frequently linked to NPs include tumor necrosis factor$\alpha$ (TNF- $\alpha$ ) or interleukin-6. The secretion of these pro-inflammatory factors was reduced by treating human AT pieces with physiological ANP concentrations in vitro, possibly through a

434 direct effect on both adipocytes and macrophages ${ }^{160}$. In this regard, reducing pro435 inflammatory cytokines and increasing adiponectin secretion from AT could indirectly ameliorate the insulin sensitizing effects by NPs (Table 1). 
Next to white AT, the presence and the importance of human brown AT (BAT) for human metabolic diseases receives increasing attention ${ }^{161-164}$, although the quantitative importance of BAT in human energy and substrate metabolism remains uncertain. BAT is a thermogenic tissue having the ability to dissipate energy in the form of heat, thereby maintaining body temperature. Substrates including glucose and free fatty acids, delivered by white AT lipolysis, are necessary for heat dissipation, a process that is mediated by mitochondrial inner membrane uncoupling protein 1 (UCP-1) ${ }^{165}$. In addition, UCP-1 may have a regulatory function in whole-body energy homeostasis ${ }^{166}$. However, most of these data are derived from rodent studies and because adult human BAT may have a differential gene expression profile as either rodent BAT or beige fat ${ }^{167}$, it physiological function in humans still needs to be determined in more detail. Support for a role of NPs in non-shivering thermogenesis was recently provided by showing that cold exposure acutely increases cardiac BNP secretion and NPRA/NPRC ratio in white AT in mice ${ }^{19}$. Mechanistic experiments indeed showed that ANP (and BNP) might activate mitochondrial biogenesis and uncoupling in human and mouse white adipocytes, via p38 MAPK/ATF2 signaling ${ }^{19}$. Chronic BNP treatment of $d b /+$ and $d b / d b$ mice further confirmed these findings, showing increased UCP-1 expression and browning of the white fat pads ${ }^{131}$. ANP treatment also enhanced mitochondrial function in human adipocytes ${ }^{168}$. Taken together, in vitro studies have shown that the NP system is able to induce a thermogenic process in the AT and to induce brown AT activation. Since cold exposure is able to increase both NPs secretion and brown AT activation, the role of NPs in white AT "browning" might be of interest in the human in vivo situation, particularly in human metabolic disease. Nevertheless, until today, the role of NPs in human brown AT remains elusive. 
The mobilization of free fatty acids from AT depots by NPs provides substrates for energy

467 production by oxidative tissues ${ }^{137,140}$. However, enhancement of AT and muscle lipid 468 oxidation has been shown to be susceptible for NPs as well. Birkenfeld et al. ${ }^{148}$ observed an acute increase in whole-body lipid oxidation (predominantly resulting from increased muscle lipid oxidation) following intravenous ANP infusion. Additionally ANP infusion leads to higher energy expenditure in the postprandial state ${ }^{143}$. The oxidative effect of ANP, as well as BNP, was later confirmed in vitro in human muscle cells. Transgenic in vivo experiments in mice showed increased skeletal muscle mitochondrial biogenesis, respiration and lipid oxidation upon chronic overexpression of BNP or cGMP-dependent protein kinase, thereby protecting for high fat diet induced obesity and glucose intolerance ${ }^{127}$. A physiological role of NPs in the regulation of skeletal muscle oxidative capacity in human primary myotubes was established by showing that ANP, BNP and cGMP analogs induce peroxisome proliferator-activated receptor gamma coactivator 1-alpha (PGC-1 $\alpha$ ) expression, mitochondrial oxidation and lipid (palmitate) oxidation in vitro ${ }^{20}$. In addition, PGC-1 $\alpha$ expression was associated with NPRA expression in skeletal muscle of healthy human subjects ${ }^{20}$. This proposes that NPs affect mitochondrial respiration and lipid oxidation in skeletal muscle through a cGMP dependent pathway, which was shown to be mediated by the induction of transcription and protein expression of PGC-1 $\alpha$ and several OXPHOS complexes (complex I and complex IV), accompanied by an unchanged peroxisome proliferator activated receptor (PPAR) $\delta$ expression and mitochondrial DNA content ${ }^{20}$.

Moreover, in skeletal muscle of obese and glucose intolerant humans and mice an altered 487 NPRA/NPRC protein ratio was recently reported ${ }^{124}$. In $d b / d b$ and $d b /+$ mice, this was accompanied with a diminished phosphorylation and activation of p38 MAPK, a downstream 
obesity-induced glucose intolerance and T2DM with BNP showed a reduced total diacylglycerol content in skeletal muscle, which was accompanied with higher oxidative capacity and PGC-1 $\alpha$ gene expression ${ }^{124}$. This observation was further confirmed in human primary myotubes, showing that increased NP mediated lipid oxidation was accompanied by reduced de novo ceramide production ${ }^{124}$ (Table 1$)$.

Yet, recent data indicate a conceivable interaction between the NPs system and an exercise induced myokine called musclin a protein homologous to members of the NPs family ${ }^{169}$ which results in the amelioration of the NPs' effectiveness ${ }^{170}$. Its physiologically relevant interaction was shown in vitro and in vivo and indicates the NPRA-mediated increase in skeletal muscle mitochondrial biogenesis to be potentiated by a musclin-NPRC interaction during exercise in mice ${ }^{170}$. Musclin is significantly upregulated in skeletal muscle of obese IR mice ${ }^{169}$ and its gene expression is known to be increased upon palmitate treatment in $\mathrm{C} 2 \mathrm{C} 12$ myotubes ${ }^{171}$ and high fat diet in rats ${ }^{172}$. Furthermore, as musclin was proposed to exert its effects on glucose uptake in skeletal muscle via PPAR- $\gamma^{173}$, this suggests a possible role for musclin in substrate metabolism which needs to be explored in humans in the future. These studies indicate the importance of NPs signaling in skeletal muscle lipid oxidative capacity, which is imperative for long-term maintenance of insulin sensitivity in obesity and T2DM.

\subsection{NP and liver function}

Hepatic IR is an additional hallmark frequently observed in the metabolic syndrome and develops in case of an imbalance between fatty acid supply and utilization of fatty acids by hepatocytes, leading to ectopic lipid accumulation and whole-body IR ${ }^{174}$. In obesity the presence of non-alcoholic fatty liver (NAFL) is frequently observed ${ }^{175}$, which may further lead to non-alcoholic steatohepatitis, liver cirrhosis or even liver carcinoma ${ }^{176}$. Recent studies show inverse relationships between NPs, in particular N-terminal-proBNP, and liver fat 
514 content in individuals without diabetes or self-reported liver disease ${ }^{177}$, as well as between

515 NPs and liver function as indicated by aminotransferases enzymes in individuals without 516 cardiovascular disease ${ }^{178}$. Additionally, NPs could ameliorate hepatic function as the

517 presence of NPs receptors was shown in the human liver ${ }^{179}$. More precisely, these receptors

518 were found on Kupffer-cells, resulting in a hepatoprotective effect of ANP by reducing

519 Kupffer-cell-derived oxidant stress ${ }^{180}$ and inhibiting lipopolysaccharides (LPS)-induced release

520 of pro-inflammatory TNF- $\alpha$ via a cGMP-mediated signaling ${ }^{181}$. ANP or its analogs inhibited

521 hepatic glycolysis and stimulated gluconeogenesis and cGMP production in perfused livers of

522 fed rats ${ }^{182}$. Besides, ANP also induced hepatic lipid oxidation in healthy lean individuals,

523 thereby reducing lipid spill-over and ectopic lipid deposition ${ }^{143}$. Consequently, lower liver

524 TAG content was observed in BNP- or cGKI-transgenic mice on a high fat diet ${ }^{127}$. These

525 findings were later confirmed in a cGKI knock out model, indicated by the presence of 526 interleukin-6 mediated liver inflammation, fasting hyperglycemia and reduced insulin

527 signaling ${ }^{183}$. These data together suggest a direct role of NPs in liver lipid catabolism (Table

528 1) next to indirect effects via AT mass reduction ${ }^{127}$.

\section{NP and control of insulin sensitivity}

A role of NPs in the regulation of insulin sensitivity is plausible since several studies indicated an inverse association between NP deficiency and IR in human cohorts ${ }^{21,24,92,113}$. Moreover, the broad range of metabolic effects in insulin sensitive tissues makes these peptides putative targets for lifestyle and exercise interventions in metabolic diseases However, unraveling the mechanistic link via which NPs signaling can modulate insulin sensitivity remains incompletely understood 
A role of NPs and their signaling pathway(s) in the control of insulin sensitivity was corroborated by BNP- and cGK-I-transgenic animals, which were protected against the

541 development of diet-induced IR and glucose intolerance ${ }^{127}$, and chronic BNP infusion studies

542 in obese diabetic $d b / d b$ mice ${ }^{124,131}$, which improved insulin sensitivity and glucose tolerance

543 and was accompanied by a reduced ectopic lipid accumulation 124,127,131. On the contrary,

544 genetic knock-down of the NPs signaling cascade impaired fasting glycemia in mice, possibly

545 reflecting an attenuated insulin-mediated regulation of hepatic gluconeogenesis ${ }^{183}$. Little is

546 known about the mechanisms responsible for the improvements in the NP-induced metabolic

547 effects, but these may relate to NP secretion as well as NPs receptor expression and post-

548 receptor signaling. Indeed, in humans, whole-body insulin sensitivity was recently shown to

549 strongly correlate with NPRA in subcutaneous AT ${ }^{153}$ and skeletal muscle ${ }^{124}$. In line, AT

$550 \quad 148,153$ and skeletal muscle ${ }^{124}$ NPRC expression was negatively associated with whole-body

551 insulin sensitivity. Additionally, NPs degradation by NEP ${ }^{74}$ may contribute to the

552 development of IR (as was shown in obese Zucker rats) ${ }^{184,185}$. Indeed NEP expression in

553 plasma and adipocytes was positively associated with obesity and cardiometabolic risk in the 554 presence of IR ${ }^{128}$.

\subsection{NP and insulin secretion}

556 In addition to changes in insulin sensitivity, NPs may also affect pancreatic insulin secretion.

557 Increased insulin levels were observed during ANP infusion in healthy subjects ${ }^{143,186}$, while

558 others showed no alterations during physiological infusion ${ }^{187}$. This effect of NPs on insulin

559 concentration could be (partly) mediated by an increased secretion, since NPRA receptors

560 were shown to be present on pancreatic $\alpha$ and $\beta$ cells ${ }^{188}$. Furthermore, $\beta$ cell insulin content,

561 fasting glycemia as well as islet size and $\beta$ cell mass were shown to be attenuated in the 
562 NPRA knock out state ${ }^{188}$, the latter being confirmed in isolated rat pancreatic islands ${ }^{189}$ 563 (Table 1).

\section{Impact of exercise/lifestyle intervention on NP-related metabolic effects}

The use of exercise as a non-pharmacological strategy to combat NP deficiency is appropriate as several studies have shown that exercise increases ANP levels, at least in healthy subjects (Figure 2) ${ }^{144,190-192}$. In particular, ANP secretion is enhanced by increasing venous return and cardiac filling pressure (i.e. cardiac output) ${ }^{193-195}$, while only slightly increasing ${ }^{193}$ or even not altering circulatory BNP levels ${ }^{194}$ in healthy volunteers, possibly indicating opposing regulation in cardiac atria and ventricles. One study reported plasma BNP levels to be positively associated with physical activity levels, although this remains controversial ${ }^{196,197}$. Recently, 7 days of bed rest induced a decrease in plasma proANP in young healthy males, which was also accompanied with a decreased insulin sensitivity ${ }^{151}$. Exercise in elderly, healthy subjects caused significantly increased proANP and N-terminal-proBNP levels ${ }^{198}$. Of interest, data about exercise effects on NPs in metabolic conditions are scarce. Tanaka et al. 199 showed that NP secretion (ANP and BNP) is more sensitive to sympathetic activity in normotensive subjects compared to hypertensive patients, where increased NPs levels may represent cardiac stress. In overweight and obese patients mid-regional-proANP concentrations increased upon incremental exhaustive exercise both before and after diet intervention, with no difference in exercise response between these conditions ${ }^{200}$. Moreover, NPs were also evaluated in relation to resistance training ${ }^{201,202}$. Resistance training induces a significant increase in N-terminal-proBNP, which might be partly due to myocardial damage 201. However, N-terminal-proBNP concentrations did not change in elderly following resistance training ${ }^{202}$. The latter two studies indicate that the effects of strength training on NPs concentrations are still controversial and thus need more investigation, especially in metabolically compromised conditions. 
With respect to CNP, exercise preconditioning (that is, an enhancement of the tolerance of an

588 ischemic heart to subsequent ischemic insult by a single bout of interval exercise) promotes

589 the secretion of CNP in rodents, thereby elevating CNP levels in the myocardium and

590 protecting against high-intensity exercise-induced myocardial injury ${ }^{203}$. Indeed, exercise

591 training (more specifically walking or walking plus resistance exercise training) increased

592 plasma CNP levels, which may be one of the mechanisms through which exercise

593 intervention may reverse endothelial-dependent dysfunction in middle-aged individuals with

594 impaired glucose tolerance ${ }^{204}$. This supports the use of (combined) exercise training to 595 prevent T2DM.

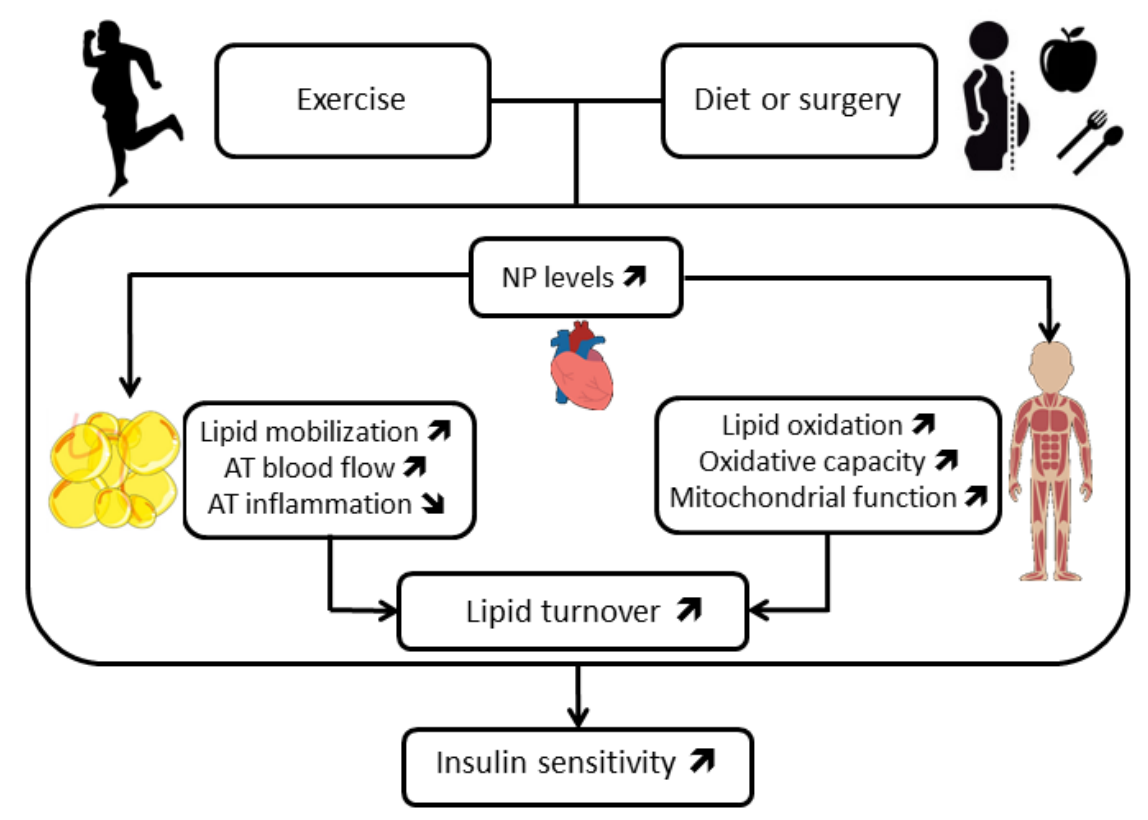

Figure 2 - Lifestyle or surgical intervention effects on natriuretic peptide levels and associated metabolic effects in humans. 
Mechanisms responsible for the exercise-/exercise training-induced normalization of the NP

603 deficiency in metabolic disease might include multiple paths, which are currently 604 incompletely understood (Figure 2). Regular physical activity ${ }^{205}$, rather than caloric 605 restriction ${ }^{200}$, augments ANP-mediated increases in AT blood flow ${ }^{192}$ and AT functional 606 NPRA receptor expression thereby presumably recovering white AT ANP responsiveness ${ }^{192,}$ $607{ }^{206}$, together resulting in an improved AT lipid mobilization process in the overweight/obese 608 state. As an alternative, water-based exercise has been shown to be not advantageous over 609 moderate intensity land-based exercise with respect to lipid mobilization or fat oxidation in 610 humans despite higher systemic ANP levels during exercise ${ }^{207}$. Moreover, exercise training 611 enhances mitochondrial function at the level of the skeletal muscle and ultimately insulin 612 sensitivity ${ }^{208}$, at least partly due to an increased NPRA expression and signaling ${ }^{208}$, the latter 613 also resulting from caloric restriction-induced weight loss ${ }^{124}$ in obese subjects ${ }^{20}$. Of interest, 614 pharmacologically improved insulin sensitivity (by the anti-diabetic drug pioglitazone) was 615 accompanied by an increased NPRA/NPRC ratio in subcutaneous AT of obese individuals with T2DM ${ }^{153}$. Liraglutide-induced weight loss in obese individuals with T2DM was 618 correlated with change in NPs levels, although the mechanism responsible remained elusive 209.

619 Diet-induced ${ }^{135}$ and gastric bypass-mediated weight loss ${ }^{125}$ confirmed the reversibility of the 620 reduced maximal ANP responsiveness in the subcutaneous AT of obese women, postulating 621 that the observed impairments in NPs-mediated metabolic effects are secondary to the obese 622 state. With respect to caloric restriction, fasting was shown to restore NPs signaling by 623 reducing NPRC expression in the AT ${ }^{126,127}$. However, weight loss studies, either involving 624 caloric restriction or gastric bypass surgery, indicated increased systemic NPs levels (i.e. NT625 proBNP) ${ }^{210-215}$, which was not confirmed in all studies 200,216,217. Comparing these 
interventions, it was recently shown that amount of weight loss is associated with the increase in systemic NPs concentrations ${ }^{218}$. Besides changing the NPs' signaling pathway and as many studies also observe changes in the inactive fragments (NT-proANP and NT-proBNP), which are not cleared by NPRC, these findings suggest not only changes in signaling but also adjustments in cardiac production and release following weight loss. In this regard, improvements in other comorbidities which could affect the NPs system following this type of interventions should be taken into account as well.

Together, these data indicate that the NPs signaling pathway may be a suitable target to improve insulin sensitivity inexercise interventions, weight loss interventions or a combination between both (Figure 2). Their modulatory effects with respect to NPs related improvements in insulin sensitivity need further investigation in human metabolic disease. However, the present clinical studies do not show a causal relationship but they do indicate the presence of a strong association between the NPs system and insulin sensitivity management, which needs further focus in upcoming human non-pharmacological intervention studies.

\section{Therapeutic opportunities for ANP in metabolic diseases}

The natriuretic deficiency present in obesity, the metabolic syndrome and T2DM is described by reduced plasma levels of NPs together with impaired tissue responses in AT and skeletal muscle tissue. Normalizing systemic NPs levels or tissue responses may therefore be imperative in the prevention of metabolic disturbances in the obese state. With respect to systemic NPs levels, pharmacological treatment with the anti-diabetic drug liraglutide was unable to acutely increase cardiac ANP secretion ${ }^{54,55,57}$. However, upon chronic treatment in obese individuals with T2DM systemic NPs levels increased, thereby being associated with the amount of induced weight loss ${ }^{209}$. This might indicate that, based on the pleiotropic 
effects of NPs in metabolic tissues, several molecular targets of the NP system may be targeted. Strategies aimed to chronically inhibit NPs degradation might be a way to sustain appropriate systemic NPs levels and thus NP signaling in metabolic tissues. Inhibiting NPRC, NEP- or IDE-mediated NPs breakdown could be suitable options in this respect as recently reviewed ${ }^{219}$. Secondly, NPs delivery may be envisioned, a therapeutic option in which adequate delivery is crucial to obtain clinical efficacy ${ }^{219}$. In addition to the use of recombinant ANP (carperitide) and BNP (nesiritide) in acute heart failure treatment ${ }^{220-222}$, the therapeutic potential of these compounds in metabolic diseases may be tested. Furthermore, selective NPRC antagonists or NPs analogs resisting NPRC-mediated clearance might be suitable as well. Finding novel peptides or optimized delivery methods will be a new frontier in the development of therapeutics for metabolic diseases in future research. In addition, to gain knowledge about causality and to identify potential determinants and mechanisms determining tissue-specific effects, more mechanistic studies in whole-body and tissuespecific knockout models of NPs or their signaling pathway are crucial. These insights may be implemented in the optimization of non-pharmacologic treatment strategies of metabolic diseases.

\section{Conclusions}

The potential role of NPs as an important metabolic target affecting insulin sensitivity in metabolically compromised conditions has been put forward over the last decade. Preclinical and clinical research indicated the presence of a NP deficiency in obesity and T2DM, which is a well-accepted anomaly that could result from inadequate cardiac NPs production and

671 secretion, as well as an increased degree of peripheral degradation. Of interest, several impairments in NPs receptor and post-receptor signaling have been observed in peripheral tissues like the AT or the skeletal muscle tissue of patients with metabolic disease, including overweight, obesity, IR and T2DM. Despite several animal and human data suggest a causal 
675 link between these NPs (signaling) deficiencies and the development of T2DM, the exact 676 molecular mechanism remains incompletely understood. Unraveling the molecular 677 background of these anomalies could therefore further highlight the emerging role of NPs in 678 metabolic diseases. From a clinical point of view, it remains important to investigate 679 therapeutic options to restore this NP deficiency. Next to implementing pharmacological 680 intervention strategies, lifestyle interventions (including physical activity and diet) are of 681 interest in the treatment of metabolic disease. Indeed, previous studies indicated diet-induced 682 weight loss and physical exercise training to sensitize NPs signaling in AT and skeletal 683 muscle tissue, two main metabolic organs with a role in obesity-related IR and T2DM, but 684 also to improve cardiac NPs secretion. However, selecting the appropriate intervention with 685 respect to reducing cardiovascular and metabolic risk factors is of special interest to further improve cardiometabolic health and reduce the development and progression of obesityrelated risk factors. Therefore, long-term human intervention studies are needed to clarify the role of NPs in the control of body weight and insulin sensitivity, including investigation of the 689 underlying molecular machinery.

\section{12. Funding}

691 The research in the authors' laboratories is funded by internal resources from Maastricht 692 University and Hasselt University.

693

694 695 
1. Shulman G. Ectopic fat in insulin resistance, dyslipidemia and cardiometabolic disease. N Engl J Med 2014; 371:1131-1141.

2. Grundy S. Obesity, metabolic syndrome, and cardiovascular disease. J Clin Endocrinol Metab 2004; 89:2595-2600.

704

3. Kahn S, Hull R, Utzschneider K. Mechanisms linking obesity to insulin resistance and type 2 diabetes. Nature 2006; 444:840-846.

4. Krotkiewski M, Björntorp P, Sjöström L, Smith U. Impact of obesity on metabolism in men and women. Importance of regional adipose tissue distribution. J Clin Invest 1983; 72:1150-1162.

5. Srdic B, Stokic E, Korac A, Ukropina M, Velickovic K, Breberina M. Morphological characteristics of abdominal adipose tissue in normal-weight and obese women of different metabolic profiles. Exp Clin Endocrinol Diabetes 2010; 118:713-718.

6. Goossens G. The role of adipose tissue dysfunction in the pathogenesis of obesity-related insulin resistance. Physiol Behav 2008; 94:206-218.

7. Unger R, Clark G, Scherer P, Orci L. Lipid homeostasis, lipotoxicity and the metabolic syndrome. Biochim Biophys Acta 2010; 1801:209-214.

8. Virtue S, Vidal-Puig A. Adipose tissue expandability, lipotoxicity and the Metabolic Syndrome--an allostatic perspective. Biochim Biophys Acta 2010; 1801:338-349.

9. Snel M, Jonker J, Schoones J, et al. Ectopic fat and insulin resistance: pathophysiology and effect of diet and lifestyle interventions. Int J Endocrinol 2012; 2012:983814.

10. Stinkens R, Goossens G, Jocken J, Blaak E. Targeting fatty acid metabolism to improve glucose metabolism. Obes Rev 2015; 16:715-757.

11. Roumen C, Blaak E, Corpeleijn E. Lifestyle intervention for prevention of diabetes: determinants of success for future implementation. Nutr Rev 2009; 67:132-146. 
12. Tuomilehto J. Nonpharmacologic therapy and exercise in the prevention of type 2 diabetes. Diabetes Care 2009; 32 Suppl 2:S189-S193.

13. Lafontan M, Moro C, Berlan M, Crampes F, Sengenes C, Galitzky J. Control of lipolysis by natriuretic peptides and cyclic GMP. Trends Endocrinol Metab 2008; 19:130-137.

14. Moro C, Smith S. Natriuretic Peptides: New Players in Energy Homeostasis. Diabetes 2009; 58:2726-2728.

15. Moro C, Lafontan M. Natriuretic peptides and cGMP signaling control of energy homeostasis. Am J Physiol Heart Circ Physiol 2013; 304:H358-H368.

16. Coué M, Moro C. Natriuretic peptide control of energy balance and glucose homeostasis. Biochimie 2016; 124:84-91.

17. Del Ry S, Cabiati M, Vozzi F, et al. Expression of C-type natriuretic peptide and its receptor NPR-B in cardiomyocytes. Peptides 2011; 32:1713-1718.

18. Volpe M. Natriuretic peptides and cardio-renal disease. Int J Cardiol 2014; 176:630-639.

19. Bordicchia M, Liu D, Amri E, et al. Cardiac natriuretic peptides act via p38 MAPK to induce the brown fat thermogenic program in mouse and human adipocytes. J Clin Invest 2012; 122:1022-1036.

20. Engeli S, Birkenfeld A, Badin P, et al. Natriuretic peptides enhance the oxidative capacity of human skeletal muscle. J Clin Invest 2012; 122:4675-4679.

21. Wang T, Larson M, Levy D, Benjamin E, Leip E, Wilson P, Vasan R. Impact of obesity on plasma natriuretic peptide levels. Circulation 2004; 109:594-600.

22. Dessi-Fulgheri $\mathrm{P}$, Sarzani R, Tamburrini P, et al. Plasma atrial natriuretic peptide and natriuretic peptide receptor gene expression in adipose tissue of normotensive and hypertensive obese patients. J Hypertension 1997; 15:1695-1699. 
23. Khan A, Cheng S, Magnusson M, et al. Cardiac natriuretic peptides, obesity, and insulin resistance: evidence from two community-based studies. J Clin Endocrinol Metab 2011; 96:3242-3249.

24. Walford G, Ma Y, Christophi C, et al. Circulating natriuretic peptide concentrations reflect changes in insulin sensitivity over time in the Diabetes Prevention Program. Diabetologia 2014; 57:935-939.

25. Magnusson M, Jujic A, Hedblad B, et al. Low plasma level of atrial natriuretic peptide predicts development of diabetes: the prospective Malmo Diet and Cancer study. J Clin Endocrinol Metab 2012; 97:638-645.

26. Lazo M, Young J, Brancati F, et al. NH2-terminal pro-brain natriuretic peptide and risk of diabetes. Diabetes 2013; 62:3189-3193

27. De Bold A, Borenstein H, Veress A, Sonnenberg H. A rapid and potent natriuretic response to intravenous injection of atrial myocardial extract in rats. Life Sci 1981; 28:89-94.

28. Kisch B. Electron microscopy of the atrium of the heart. I Guinea pig. Exp Med Surg $1956 ; 14: 99-112$

29. Kangawa K, Fukuda A, Minamino N, Matsuo H. Purification and complete amino acid sequence of beta-rat atrial natriuretic polypeptide (beta-rANP) of 5,000 daltons. Biochem Biophys Res Commun 1984; 119:933-940.

30. Komatsu Y, Nakao K, Suga S, et al. C-type natriuretic peptide (CNP) in rats and humans. Endocrinology 1991; 129:1104-1106.

31. Sudoh T, Minamino N, Kangawa K, Matsuo H. C-type natriuretic peptide (CNP): a new member of natriuretic peptide family identified in porcine brain. Biochem Biophys Res Commun 1990; 168:863-870. 
32. Moyes A, Khambata R, Villar I, et al. Endothelial C-type natriuretic peptide maintains vascular homeostasis. J Clin Invest 2014; 124:4039-4051.

33. Kake T, Kitamura H, Adachi Y, et al. Chronically elevated plasma C-type natriuretic peptide level stimulates skeletal growth in transgenic mice. Am J Physiol Endocrinol Metab 2009; 297:E1339-E1348.

34. Inuzuka M, Tamura $\mathrm{N}$, Yamada $\mathrm{N}$, et al. C-type natriuretic peptide as a new regulator of food intake and energy expenditure. Endocrinology 2010; 151:3633-3642.

35. Yamada-Goto N, Katsuura G, Ebihara K, et al. Intracerebroventricular administration of C-type natriuretic peptide suppresses food intake via activation of the melanocortin system in mice. Diabetes 2013; 62:1500-1504.

36. Park B, Kim S, Kim S, Noh H, Cho C, Kim S. Characteristics of dendroaspis natriuretic peptide and its receptor in streptozotocin-induced diabetic rats. Mol Med Rep 2015; 12:2969-2976.

37. Gardner D, Chen S, Glenn D, Grigsby C. Molecular biology of the natriuretic peptide system: implications for physiology and hypertension. Hypertension 2007; 49:419-426.

38. Nishikimi T, Kuwahara K, Nakao K. Current biochemistry, molecular biology, and clinical relevance of natriuretic peptides. J Cardiol 2011; 57:131-140.

39. Nakao K, Ogawa Y, Suga S, Imura H. Molecular biology and biochemistry of the natriuretic peptide system. I: Natriuretic peptides. J Hypertension 1992; 10:907-912.

40. Yan W, Wu f, Morser J, Wu Q. Corin, a transmembrane cardiac serine protease, acts as a pro-atrial natriuretic peptide-converting enzyme. Proc Natl Acad Sci USA 2000; 97:85258529.

41. Clerico A. Natriuretic peptides - The hormones of the heart. Clerico A, Emdin M, Eds. Springer Science+ Business Media, 2006. 
42. Morgenthaler N, Struck J, Thomas B, Bergmann A. Immunoluminometric assay for the midregion of pro-atrial natriuretic peptide in human plasma. Clin Chem 2004; 50:234236.

43. Nannipieri M, Seghieri G, Catalano C, Prontera T, Baldi S, Ferrannini E. Defective regulation and action of atrial natriuretic peptide in type 2 diabetes. Horm Metab Res

44. Nakayama K. Furin: a mammalian subtilisin/Kex2p-like endoprotease involved in processing of a wide variety of precursor proteins. Biochem J 1997; 327:625-635.

803

49. Yuan K, Jin X, Park W, et al. Modification of atrial natriuretic peptide system in cold-

45. Potter L. Natriuretic peptide metabolism, clearance and degradation. FEBS J 2011; 278:1808-1817.

46. McGrath $\mathrm{M}$, de Bold $\mathrm{M}$, de Bold A. The endocrine function of the heart. Trends Endocrinol Metab 2005; 16:469-477.

47. Chun S, Hyun J, Kwak Y, et al. Hypoxic activation of the atrial natriuretic peptide gene promoter through direct and indirect actions of hypoxia-inducible factor-1. Biochem $J$ 2003; 370:149-157.

48. Fregly M, Kikta D, Threatte R, et al. Development of hypertension in rats during chronic exposure to cold. J Appl Physiol 1989; 66:741-749. induced hypertensive rats. Regul Pept 2009; 154:112-120.

50. Ogawa Y, Itoh H, Nakao K. Molecular biology and biochemistry of natriuretic peptide family. Clin Exp Pharmacol Physiol 1995; 22:49-53.

51. Ogawa T, de Bold A. Brain natriuretic peptide production and secretion in inflammation. J Transplant 2012; 2012:962347. 
52. Meirovich Y, Veinot J, de Bold M, et al. Relationship between natriuretic peptides and inflammation: proteomic evidence obtained during acute cellular cardiac allograft rejection in humans. J Heart Lung Transplant 2008; 27:31-37.

53. Kim M, Platt M, Shibasaki T, et al. GLP-1 receptor activation and Epac2 link atrial natriuretic peptide secretion to control of blood pressure. Nat Med 2013; 19:567-575.

54. Asmar A, Simonsen L, Asmar M, et al. Renal Extraction and Acute Effects of Glucagonlike peptide-1 on Central and Renal Hemodynamics in Healthy Men. Am J Physiol Endocrinol Metab 2015; ajpendo 004292014.

55. Asmar A, Simonsen L, Asmar M, et al. Glucagon-like peptide-1 does not have acute effects on central or renal hemodynamics in patients with type 2 diabetes without nephropathy. Am J Physiol Endocrinol Metab 2016; 310:E744-E753.

56. Lovshin J, Bamie A, DeAlmeida A, et al. Liraglutide Promotes Natriuresis but Does Not Increase Circulating Levels of Atrial Natriuretic Peptide in Hypertensive Subjects With Type 2 Diabetes. Diabetes Care 2015; 38:132-139.

57. Rudovic N, Pivovarova O, Gögebakan Ö, et al. Effect of Exogenous Intravenous Administrations of GLP-1 and/or GIP on Circulating Pro-Atrial Natriuretic Peptide in Subjects With Different Stages of Glucose Tolerance. Diabetes Care 2015; 38:e7-e8.

58. Maffei S, Del Ry S, Prontera C, Clerico A. Increase in circulating levels of cardiac natriuretic peptides after hormone replacement therapy in postmenopausal women. Clin Sci 2001; 101:447-453.

59. Clerico A, Ry Silvia D, Maffei S, Prontera C, Emdin M, Giannessi D. The circulating levels of cardiac natriuretic hormones in healthy adults: effects of age and sex. Clin Chem Lab Med 2002; 40:371. 
60. Hamada M, Shigetmatsu Y, Takezaki M, Ikeda S, Ogimoto A. Plasma levels of atrial and brain natriuretic peptides in apparently healthy subjects: Effects of sex, age, and hemoglobin concentration. Int J Cardiol 2017; 228:599-604.

61. Clerico A, Passino C, Emdin N. When gonads talk to the heart sex hormones and cardiac endocrine function. J Am Coll Cardiol 2011; 58:627-628.

62. Lam C, Cheng S, Choong K, et al. Influence of sex and hormone status on circulating natriuretic peptides. J Am Coll Cardiol 2011; 58:618-626.

63. Goharian T, Gimsing A, Goetze, J, Faber J, Andersen L, Grontved A, Jeppesen J. Midregional pro-atrial natriuretic peptide and blood pressure in adolescents: effect of gender and pubertal stage. Blood Press 2015; 24:347-352.

64. Mahmoodzadeh S, Pham T, Kuehne A, et al. 17 $\beta$-Estradiol-induced interaction of ER $\alpha$ with NPPA regulates gene expression in cardiomyocytes. Cardiovasc Res 2012; 96:411421.

65. Sellitti D, Koles N, Mendonca M. Regulation of C-type natriuretic peptide expression. Peptides 2011; 32:1964-1971.

66. Khun M. Molecular physiology of membrane guanylyl cyclase receptors. Physiol Rev 2016; 96:751-804.

67. Stoupakis G, Klapholz M. Natriuretic peptides: biochemistry, physiology, and therapeutic role in heart failure. Heart Dis 2003; 5:215-223.

68. Yasoda A, Ogawa Y, Suda M, et al. Natriuretic peptide regulation of endochondral ossification: evidence for possible roles of the $\mathrm{C}$ type natriuretic peptide/guanylyl cyclase-B pathway. J Biochem 1998; 273:11695-11700.

69. Misono K, Philo J, Arakawa T, Ogata C, Qiu Y, Ogawa H, Young H. Structure, signaling mechanism and regulation of the natriuretic peptide receptor guanylate cyclase. FEBS $J$ 2011; 278:1818-1829. 
70. Pandey K. Endocytosis and Trafficking of Natriuretic Peptide Receptor-A: Potential Role of Short Sequence Motifs. Membranes (Basel) 2015; 5:253-287.

71. Suga S, Nakao K, Hosoda K, et al. Receptor selectivity of natriuretic peptide family, atrial natriuretic peptide, brain natriuretic peptide, and $\mathrm{C}$-type natriuretic peptide. Endocrinology 1992; 130:229-239.

72. Pandey K. Kinetic analysis of internalization, recycling and redistribution of atrial natriuretic factor-receptor complex in cultured vascular smooth-muscle cells. Liganddependent receptor down-regulation. Biochem J 1992; 288:55-61.

73. Matsukawa N, Grzesik W, Takahashi N, Pandey K, Pang S, Yamauchi M, Smithies O. The natriuretic peptide clearance receptor locally modulates the physiological effects of the natriuretic peptide system. Proc Natl Acad Sci USA 1999; 96:7403-7408.

74. Kenny A, Bourne A, Ingram J. Hydrolysis of human and pig brain natriuretic peptides, urodilatin, C-type natriuretic peptide and some C-receptor ligands by endopeptidase24.11. Biochem J 1993; 1:83-88.

75. Schling P, Löffer G. Cross talk between adipose tissue cells: impact on pathophysiology. New Physiol Sci 2002; 17:99-104

76. Ralat L, Guo Q, Ren M, Funke T, Dickey D, Potter L, Tang W. Insulin-degrading enzyme modulates the natriuretic peptide-mediated signaling response. J Biol Chem 2011; 286:4670-4679.

77. Brandt I, Lambeir A, Ketelslegers J, Vanderheyden M, Scharpé S, De Meester I. Dipeptidyl-peptidase IV converts intact B-type natriuretic peptide into its des-SerPro form. Clin Chem 2006; 52:82-87.

78. Sarzani R, Dessi-Fulgheri P, Paci V, Espinosa E, Rappelli A. Expression of natriuretic peptide receptors in human adipose and other tissues. J Endocrinol Invest 1996; 19:581585. 
79. Bryan P, Smirnov D, Smolenski A, et al. A sensitive method for determining the phosphorylation status of natriuretic peptide receptors: cGK-Ialpha does not regulate NPR-A. Biochemistry 2006; 45:1295-1303.

80. Nagase M, Katafuchi T, Hirose S, Fujita T. Tissue distribution and localization of natriuretic peptide receptor subtypes in stroke prone spontaneously hypertensive rats. $J$ Hypertens 1997; 15:1235-1243.

81. Pivovarova O, Gögebakan Ö, Klöting N, et al. Insulin up-regulates natriuretic peptide clearance receptor expression in the subcutaneous fat depot in obese subjects: a missing link between CVD risk and obesity. J Clin Endocrinol Metab 2012; 94:E731-E739.

82. Smith J, Fahrenkrug J, Jorgensen H, Christoffersen C, Goetze J. Diurnal gene expression of lipolytic natriuretic peptide receptors in white adipose tissue. Endocr Connect 2015; 4:206-214.

83. Martino T, Tata N, Belsham D, et al. Disturbed diurnal rhythm alters gene expression and exacerbates cardiovascular disease with rescue by resynchronization. Hypertension 2007; 49:1104-1113.

84. Goetze J, Jorgensen H, Sennels H, Fahrenkrug J. Diurnal plasma concentrations of natriuretic propeptides in healthy young males. Clin Chem 2012; 58:789-792.

85. Goetze J, Georg B, Jorgensen H, Fahrenkrug J. Chamber-dependent circadian expression of cardiac natriuretic peptides. Regul Pept 2010; 160:140-145.

86. Nakatsuji H, Maeda N, Hibuse $\mathrm{T}$, et al. Reciprocal regulation of natriuretic peptide receptors by insulin in adipose cells. Biochem Biophys Res Comm 2010; 392:100-105.

87. Collins S. A heart-adipose tissue connection in the regulation of energy metabolism. Nat Rev Endocrinol 2014; 10:157-163. 
88. Das $\mathrm{S}$, Drazner $\mathrm{M}$, Dries $\mathrm{D}$, et al. Impact of body mass and body composition on circulating levels of natriuretic peptides: results from the Dallas Heart Study. Circulation $2005 ; \mathbf{1 1 2}: 2163-2168$

89. Cannone V, Boerrigter G, Cataliotti A, et al. A genetic variant of the atrial natriuretic peptide gene is associated with cardiometabolic protection in the general community. $J$ Am Coll Cardiol 2011; 58:629-636.

90. Sugisawa T, Kishimoto I, Kokubo Y, Nagumo A, Makino H, Miyamoto Y, Yoshimasa Y. Visceral fat is negatively associated with B-type natriuretic peptide levels in patients with advanced type 2 diabetes. Diabetes Res Clin Pract 2010; 89:174-180.

91. Buglioni A, Cannone V, Cataliotti A, et al. Circulating aldosterone and natriuretic peptides in the general community: relationship to cardiorenal and metabolic disease. Hypertension 2015; 65:45-53.

92. Olsen M, Hansen T, Christensen M, et al. N-terminal pro brain natriuretic peptide is inversely related to metabolic cardiovascular risk factors and the metabolic syndrome. Hypertension 2005; 46:660-666.

93. Taylor J, Christenson R, Rao K, Jorge M, Gottlieb S. B-Type natriuretic peptide and Nterminal pro B-type natriuretic peptide are depressed in obesity despite higher left ventricular end diastolic pressures. Am Heart J 2006; 152:1071-1076.

94. Grandi A, Laurita E, Selva E, et al. Natriuretic peptides as markers of preclinical cardiac disease in obesity. Eur J Clin Invest 2004; 34:342-348.

95. Abdulle A, Nagelkerke N, Adem A, et al. Plasma N terminal pro-brain natriuretic peptide levels and its determinants in a multi-ethnic population. J Hum Hypertens 2007; 21:647653.

96. Sarzani R, Strazzullo P, Salvi F, et al. Natriuretic peptide clearance receptor alleles and susceptibility to abdominal adiposity. Obes Res 2004; 12:351-356. 
97. Cheng S, Fox C, Larson M, et al. Relation of visceral adiposity to circulating natriuretic peptides in ambulatory individuals. Am J Cardiol 2011; 108:979-984.

98. Trevisan R, Fioretto P, Semplicini A, et al. Role of insulin and atrial natriuretic peptide in sodium retention in insulin-treated IDDM patients during isotonic volume expansion. Diabetes 1990; 39:289-298.

99. Aboucharcra S, Baines A, Zinman B, Skorecki K, Logan A. Insulin blunts the natriuretic action of atrial natriuretic peptide in hypertension. Hypertension 1994; 56:1054-1058.

100. Neeland I, Winders B, Ayers C, et al. Higher natriuretic peptide levels associate with a favorable adipose tissue distribution profile. J Am Coll Cardiol 2013; 62:752-760.

101. Hermann-Arnhof K, Hanusch-enserer U, Kaestenbauer T, et al. N-terminal pro-B-type natriuretic peptide as an indicator of possible cardiovascular disease in severely obese individuals: comparison with patients in different stages of heart failure. Clin Chem 2005; 51:138-143.

102. Burnett J, Granger J, Opgenorth T. Effects of synthetic atrial natriuretic factor on renal function and renin release. Am J Physiol 1984; 247:F863-F866.

103. Shi S, Nguyen H, Sharma G, Navar L, Pandey K. Genetic disruption of atrial natriuretic peptide receptor-A alters renin and angiotensin II levels. Am J Physiol Renal Physiol 2001; 281:F665-F673.

104. Asferg C, Andersen U, Linneberg A, Hedley P, Christiansen M, Goetze J, Jeppesen J. Serum proatrial natriuretic peptide does not increase with higher systolic blood pressure in obese men. Heart 2017; 103:154-158.

105. Jordan J, Engeli S. Obesity, hypertension, and cardiovascular health: is there anything poor Cassandra tries to tell us? J Hypertens 2012; 30:1103-1105.

106. Jordan J, Birkenfeld A. Cardiometabolic crosstalk in obesity-associated arterial hypertension. Rev Endocr Metab Disord 2016; 17:19-28. 
107. Gruden G, Landi A, Bruno G. Natriuretic peptides, heart, and adipose tissue: new findings and future developments for diabetes research. Diabetes Care 2014; 37:28992908.

108. Hammerer-Lercher A, Ludwig W, Falkensammer G, et al. Natriuretic peptides as markers of mild forms of left ventricular dysfunction: effects of assays on diagnostic performance of markers. Clin Chem 2004; 50:1174-1183.

109. Wong C, O’Moore-Sullivan T, Leano R, Byrne N, Beller E, Marwick T. Alterations of left ventricular myocardial characteristics associated with obesity. Circulation 2004; 110:3081-3087.

110. Jujic A, Nilsson P, Persson M, et al. Atrial Natriuretic Peptide in the High Normal Range Is Associated With Lower Prevalence of Insulin Resistance. J Clin Endocrinol Metab 2016; 414:1372-1380.

111. Brutsaert E, Biggs M, Delaney J, et al. Longitudinal assessment of N-terminal pro-Btype natriuretic peptide and risk of diabetes in older adults: The cardiovascular health study. Metabolism 2016; 65:1489-1497.

112. Kim F, Biggs M, Kizer J, et al. Brain natriuretic peptide and insulin resistance in older adults. Diabet Med 2017; 34:235-238.

113. Kroon M, van den Hurk K, Alssema M, Kamp O, Stehouwer C, Henry R. Prospective associations of B-type natriuretic peptide with markers of left ventricular function in individuals with and without type 2 diabetes: an 8 -year follow-up of the Hoorn Study. Diabetes Care 2012; 35:2510-2514.

114. Everett B, Cook N, Chasman D, et al. Prospective evaluation of B-type natriuretic peptide concentrations and the risk of type 2 diabetes in women. Clin Chem 2013; 59:557-565. 
115. Pfister R, Sharp S, Luben R, et al. Mendelian randomization study of B-type natriuretic peptide and type 2 diabetes: evidence of causal association from population studies. PLoS Med 2011; 8:e1001112.

116. Cannone V, Cefalu A, Noto D, et al. The atrial natriuretic peptide genetic variant rs5068 is associated with a favorable cardiometabolic phenotype in a Mediterranean population. Diabetes Care 2013; 36:2850-2856.

117. Heinisch B, Vila G, Resl M, et al. B-type natriuretic peptide (BNP) affects the initial response to intravenous glucose: a randomised placebo-controlled cross-over study in healthy men. Diabetologia 2012; 55:1400-1405.

118. Jujic A, Nilsson P, Engström G, Hedblad B, Melander O, Magnusson M. Atrial natriuretic peptide and type 2 diabetes development - biomarker and genotype association study. PLoS One 2014; 9:e89201.

119. Meirhaeghe A, Sandhu M, McCarthy M, et al. Association between the T-381C polymorphism of the brain natriuretic peptide gene and risk of type 2 diabetes in human populations. Human Molecular Genetics 2007; 16:1343-1350.

120. Cannone V, Huntley B, Olson T, et al. Atrial natriuretic peptide genetic variant rs5065 and risk for cardiovascular disease in the general community: a 9-year follow-up study. Hypertension 2013; 62:860-865.

121. Maack T, Suzuki M, Almeida F, Nussenzveig D, Scarborough R, McEnroe G, Lewicki J. Physiological role of silent receptors of atrial natriuretic factor. Science 1987; 238:675678.

122. Bordicchia M, Ceresiani M, Pavani M, et al. Insulin/glucose induces natriuretic peptide clearance receptor in human adipocytes: a metabolic link with the cardiac natriuretic pathway. Am J Physiol Regul Integr Comp Physiol 2016; 311:R104-R114. 
123. Halbrik M, Norrelund H, Moller N, Schmitz O, Botker H, Wiggers. Short-term changes in circulating insulin and free fatty acids affect Nt-pro-BNP levels in heart failure patients. Int J Cardiol 2010; 144:140-142.

124. Coué M, Badin P, Vila I, et al. Defective Natriuretic Peptide Receptor Signaling in Skeletal Muscle Links Obesity to Type 2 Diabetes. Diabetes 2015; 64:4033-4045.

125. Rydén M, Backdahl J, Petrus P, et al. Impaired atrial natriuretic peptide-mediated lipolysis in obesity. Int J Obes 2016; 40:714-20

126. Sarzani R, Paci V, Zingaretti C, et al. Fasting inhibits natriuretic peptides clearance receptor expression in rat adipose tissue. J Hypertens 1995; 13:1241-1246.

127. Miyashita K, Itoh $\mathrm{H}$, Tsujimoto $\mathrm{H}$, et al. Natriuretic peptides/cGMP/cGMP-dependent protein kinase cascades promote muscle mitochondrial biogenesis and prevent obesity. Diabetes 2009; 58:2880-2892.

128. Standeven K, Hess K, Carter A, et al. Neprilysin, obesity and the metabolic syndrome. Int J Obes 2011; 35:1031-1040.

129. Minami J, Nishikimi T, Matsuoka H. Plasma brain natriuretic peptide and $\mathrm{N}$ terminal proatrial natriuretic peptide levels in obese patients: a cause or result of hypertension. Circulation 2004; 110:e76.

130. Mizuno Y, Harada E, Katoh D, et al. Cardiac production of B-type natriuretic peptide is inversely related to the plasma level of free fatty acids in obese individuals — possible involvement of the insulin resistance. Endocr J 2013; 60:87-95.

131. Plante E, Menaouar A, Danalache B, Broderick T, Jankowski M, Gutkowska J. Treatment with brain natriuretic peptide prevents the development of cardiac dysfunction in obese diabetic db/db mice. Diabetologia 2014; 57:1257-1267.

132. Cabiati M, Raucci S, Liistro T, et al. Impact of obesity on the expression profile of natriuretic peptide system in a rat experimental model. PLoS One 2013; 8:e72959. 
133. Maisal A. B-type natriuretic peptide levels: diagnostic and prognostic in congestive heart failure: what's next. Circulation 2002; 105:2328-2331.

134. Sengenes C, Berlan M, De Glisezinski I, Lafontan M, Galitzky J. Natriuretic peptides: a new lipolytic pathway in human adipocytes. FASEB J 2000; 14:1345-1351.

135. Sengenès C, Zakaroff-Girard A, Moulin A, et al. Natriuretic peptide-dependent lipolysis in fat cells is a primate specificity. Am J Physiol Regul Integr Comp Physiol 2002; 283:R257-R265.

136. Sengenes C, Bouloumie A, Hauner H, Berlan M, Busse R, Lafontan M, Galitzky J. Involvement of a cGMP-dependent pathway in the natriuretic peptide-mediated hormone-sensitive lipase phosphorylation in human adipocytes. J Biol Chem 2003; 278:48617-48626.

137. Birkenfeld A, Boschmann M, Moro C, et al. Lipid mobilization with physiological atrial natriuretic peptide concentrations in humans. J Clin Endocrinol Metab 2005; 90:36223628.

138. Ahmadian M, Abbott M, Tang T, et al. Desnutrin/ATGL is regulated by AMPK and is required for a brown adipose phenotype. Cell Metab 2011; 13:739-748.

139. Zimmerman R, Straus J, Haemmerle G, et al. Fat mobilization in adipose tissue is promoted by adipose triglyceride lipase. Science 2004; 306:1383-1386.

140. Galitzky J, Sengenes C, Thalamas C, Marques M, Senard J, Lafontan M, Berlan M. The lipid-mobilizing effect of atrial natriuretic peptide is unrelated to sympathetic nervous system activation or obesity in young men. J Lipid Res 2001; 42:536-544.

141. Birkenfeld A, Boschmann M, Moro C, et al. Beta-adrenergic and Atrial Natriuretic Peptide Interactions on Human Cardiovascular and Metabolic Regulation. J Clin Endocrinol Metab 2006; 91:5069-5075. 
1061

1062

1063

1064

1065

1066

1067

1068

1069

1070

1071

1072

1073

1074

1075

1076

1077

1078

1079

1080

1081

1082

1083

1084

142. Moro C, Galitzky J, Sengenes C, Crampes F, Lafontan M, Berlan M. Functional and pharmacological characterization of the natriuretic peptide-dependent lipolytic pathway in human fat cells. J Pharmacol Exp Therp 2004; 308:984-992.

143. Birkenfeld A, Budziarek P, Boschmann M, et al. Atrial natriuretic peptide induces postprandial lipid oxidation in humans. Diabetes 2008; 57:3199-3204.

144. Moro C, Crampes F, Sengenes C, et al. Atrial natriuretic peptide contributes to physiological control of lipid mobilization in humans. FASEB J 2004; 18:908-910.

145. Langin D, Dicker A, Tavernier G, et al. Adipocyte lipases and defect of lipolysis in human obesity. Diabetes 54:3190-3197.

146. Rydén M, Jocken J, van Harmelen V, et al. Comparative studies of the role of hormonesensitive lipase and adipose triglyceride lipase in human fat cell lipolysis. Am J Physiol Endocrinol Metab 2007; 292:E1847-E18455.

147. Jocken J, Blaak E. Catecholamine-induced lipolysis in adipose tissue and skeletal muscle in obesity. Physiol Behav 2008; 94:219-230.

148. Verboven K, Hansen D, Moro C et al. Attenuated atrial natriuretic peptide-mediated lipolysis in subcutaneous adipocytes of obese type 2 diabetic men. Clin Sci (Lond) 2016; 130:1105-1114.

149. Dicker A, Aström G, Wahlén K, et al. Primary differences in lipolysis between human omental and subcutaneous adipose tissue observed using in vitro differentiated adipocytes. Horm Metab Res 2009; 41:350-355.

150. Endre T, Mattiasson I, Berglund G, Hulthén U. Insulin and renal sodium retention in hypertension-prone men. Hypertension 1994; 23:313-319.

151. Zois N, Terzic D, Faerch K, et al. Effect of pancreatic hormones on pro-atrial natriuretic peptide in humans. EBioMedicine 2017; 17:88-94. 
152. Moro C, Polak J, Richterova B, et al. Differential regulation of atrial natriuretic peptides and adrenergic receptor dependent lipolytic pathways in human adipose tissue. Metabolism 2005; 54:122-131.

153. Kovacova Z, Tharp W, Liu D, Wei W, Xie H, Collins S, Pratley R. Adipose tissue natriuretic peptide receptor expression is related to insulin sensitivity in obesity and diabetes. Obesity 2016; 24:820-828.

154. Arora P, Wu C, Hamid T, et al. Acute Metabolic Influences on the Natriuretic Peptide System in Humans. J Am Coll Cardiol 2016; 67:804-812.

155. Arora $\mathrm{P}, \mathrm{Wu} \mathrm{C}$, Khan $\mathrm{A}$, et al. Atrial natriuretic peptide is negatively regulated by microRNA-425. J Clin Invest 2013; 123:3378-3382.

156. Tsukamoto O, Fujita M, Kato M, et al. Natriuretic peptides enhance the production of adiponectin in human adipocytes and in patients with chronic heart failure. J Am Coll Cardiol 2009; 53:2070-2077.

157. Birkenfeld A, Boschmann M, Engeli S, Moro C, Arafat A, Luft F, Jordan J. Atrial natriuretic peptide and adiponectin interactions in man. PLoS One 2012; 7:e43238.

158. Wannamethee S, Welsh P, Whincup P, Sawar N, Thomas M, Gudnarsson V, Sattar N. High adiponectin and increased risk of cardiovascular disease and mortality in asymptomatic older men: does NT-proBNP help to explain this association. Eur $J$ Cardiovasc Prev Rehabil 2011; 18:65-71.

159. Nakanishi K, Nishida M, Yamamoto R, Koseki M, Moriyama T, Yamauchi-Takihara K. Association between $\mathrm{N}$-terminal pro-brain natriuretic peptide and adiponectin in healthy Japanese men. Clin Chim Acta 2016; 460:138-141

160. Moro C, Klimcakova E, Lolmède $\mathrm{K}$, et al. Atrial natriuretic peptide inhibits the production of adipokines and cytokines linked to inflammation and insulin resistance in human subcutaneous adipose tissue. Diabetologia 2007; 50:1038-1047. 
161. Van Marken Lichtenbelt W, Vanhommerig J, Smulders N, et al. Cold-activated brown adipose tissue in healthy men. $N$ Engl J Med 2009; 360:1500-1508.

162. Virtanen K, Lidell M, Orava J, et al. Functional brown adipose tissue in healthy adults. $N$ Engl J Med 2009; 360:1518-1525.

163. Cypess A, Lehman S, Williams G, et al. Identification and importance of brown adipose tissue in adult humans. $N$ Engl J Med 2009; 360:1509-1517.

164. Schrauwen P, van Marken Lichtenbelt W. Combatting type 2 diabetes by turning up the heat. Diabetologia 2016; 59:2269-2279.

165. Cannon B, Nedergaard J. Brown adipose tissue: function and physiological significance. Physiol Rev 2004; 84:277-359.

166. Feldmann H, Golozoubova V, Cannon B, Nedergaard J. UCP1 ablation induces obesity and abolishes diet-induced thermogenesis in mice exempt from thermal stress by living at thermoneutrality. Cell Metab 2009; 9:203-209.

167. Park J, Hur W, Lee S. Intricate Transcriptional Networks of Classical Brown and Beige Fat Cells. Front Endocrinol 2015; 6:124.

168. Souza S, Chau M, Yang Q, et al. Atrial natriuretic peptide regulates lipid mobilization and oxygen consumption in human adipocytes by activating AMPK. Biochm Biophys Res Comm 2011; 410:398-403.

169. Nishizawa H, Matsuda M, Yamada Y, et al. Musclin, a novel skeletal muscle-derived secretory factor. J Biol Chem 2004; 279:19391-19395.

170. Subbotina E, Sierra A, Zhu Z, et al. Musclin is an activity-stimulated myokine that enhances physical endurance. Proc Natl Acad Sci USA 2015; 112:16042-16047.

171. Gu N, Guo Q, Mao K, et al. Palmitate increases musclin gene expression through activation of PERK signaling pathway in C2C12 myotubes. Biochem Biophys Res Commun 2015; 467:521-526. 
172. Yu J, Zheng J, Liu X, Feng Z, Zhang X, Cao L, Zhou Z. Exercise improved lipid metabolism and insulin sensitivity in rats fed a high-fat diet by regulating glucose transporter 4 (GLUT4) and musclin expression. Braz J Med Biol Res 2016; 49:e5129.

173. Liu Y, Huo X, Pang X, Zong Z, Meng X, Liu G. Musclin inhibits insulin activation of Akt/protein kinase B in rat skeletal muscle. J Int Med Res 2008; 36:496-504.

174. Birkenfeld A, Shulman G. Nonalcoholic fatty liver disease, hepatic insulin resistance, and type 2 diabetes. Hepatology 2014; 59:713-723.

175. Gaggini M, Morelli M, Buzzigoli E, DeFronzo R, Bugianese E, Gastaldelli A. Nonalcoholic fatty liver disease (NAFLD) and its connection with insulin resistance, dyslipidemia, atherosclerosis and coronary heart disease. Nutrients 2013; 5:1544-1560.

176. Day C. Pathogenesis of steatohepatitis. Best Pract Res Clin Gastroenterology 2002; 16:663-678.

177. Sanchez O, Lazo-Elizondo M, Zeb I, et al. Computerized tomography measured liver fat is associated with low levels of N-terminal pro-brain natriuretic protein (NT-proBNP) Multi-Ethnic Study of Atherosclerosis. Metabolism 2016; 65:728-735.

178. Lazo M, Rubin J, Clark J, et al. The Association of Liver Enzymes with Biomarkers of Subclinical Myocardial Damage and Structural Heart Disease. J Hepatol 2015; 62:841847.

179. Vollmar A, Paumgartner G, Gerbes A. Differential gene expression of the three natriuretic peptides and natriuretic peptide receptor subtypes in human liver. Gut 1997; 40:145-150.

180. Bilzer M, Jaeschke H, Vollmar A, Paumgartner G, Gerbes A. Prevention of Kupffer cellinduced oxidant injury in rat liver by atrial natriuretic peptide. Am J Physiol 1999; 276:G1137-G1144. 
181. Kiemer A, Baron A, Gerbes A, Bilzer M, Vollmar A. The atrial natriuretic peptide as a regulator of Kupffer cell functions. Shock 2002; 17:365-371.

182. Rashed H, Nair B, Patel T. Regulation of hepatic glycolysis and gluconeogenesis by atrial natriuretic peptide. Arch Biochem Biophys 1992; 298:640-645.

183. Lutz S, Hennige A, Feil S, Peter A, Gerling A, Machann J. Genetic ablation of cGMPdependent protein kinase type I causes liver inflammation and fasting hyperglycemia. Diabetes 2011; 60:1566-1576.

184. Arbin V, Claperon N, Fournié-Zaluski M, Roques B, Peyroux J. Acute effect of the dual angiotensin-converting enzyme and neutral endopeptidase 24-11 inhibitor mixanpril on insulin sensitivity in obese Zucker rat. Br J Pharmacol 2001; 133:495-502.

185. Arbin V, Claperon N, Fournié-Zaluski M, Roques B, Peyroux J. Effects of dual angiotensin-converting enzyme and neutral endopeptidase $24-11$ chronic inhibition by mixanpril on insulin sensitivity in lean and obese Zucker rats. J Cardiovasc Pharmacol $2003 ; 41: 254-264$.

186. Uehlinger D, Weidmann $\mathrm{P}$, Gnädinger $\mathrm{M}$, et al. Increase in circulating insulin induced by atrial natriuretic peptide in normal humans. J Cardiovasc Pharmacol 1986; 8:1122-1129.

187. Ferrari P, Shaw S, Riesen W, Weidmann P. Plasma insulin during physiological and pathophysiological changes in atrial natriuretic factor. Eur J Clin Pharmacol 1992; 42:453-455.

188. Ropero A, Soriano S, Tudurí E, et al. The atrial natriuretic peptide and guanylyl cyclasea system modulates pancreatic betacell function. Endocrinology 2010; 151:3665-3674.

189. You H, Laychock S. Atrial natriuretic peptide promotes pancreatic islet beta-cell growth and Akt/Foxo1a/cyclin D2 signaling. Endocrinology 2009; 150:5455-5465. 
190. Moro C, Polak J, Hejnova J, et al. Atrial natriuretic peptide stimulates lipid mobilization during repeated bouts of endurance exercise. Am J Physiol Endocrinol Metab 2006; 290:E864-E869.

191. Moro C, Pillard F, de Glisezinski I, et al.Exercise-induced lipid mobilization in subcutaneous adipose tissue is mainly related to natriuretic peptides in overweight men. Am J Physiol Endocrinol Metab 2008; 295:E505-E513.

192. Moro C, Pillard F, De Glisezinski I, et al. Training Enhances ANP Lipid-Mobilizing Action in Adipose Tissue of Overweight Men. Medicine \& Science in Sports \& Exercise 2005; 37:1126-1132.

193. Barletta G, Stefani L, Del Bene R, et al. Effects of exercise on natriuretic peptides and cardiac function in man. Int J Cardiol 1998; 65:217-225.

194. Kjaer A, Appel J, Hildebrandt P, Petersen C. Basal and exercise-induced neuroendocrine activation in patients with heart failure and in normal subjects. Eur J Heart Fail 2004; 6:29-39.

195. Mandroukas A, Metaxas T, Heller J, et al. The effect of different exercise-testing protocols on atrial natriuretic peptide. Clin Physiol Funct Imaging 2011; 31:5-10.

196. Steele I, McDowell G, Moore A, Campbell N, Shaw C, Buchanan K, Nicholls D. Responses of atrial natriuretic peptide and brain natriuretic peptide to exercise in patients with chronic heart failure and normal control subjects. Eur J Clin Invest 1997; 27:270276.

197. Kato M, Kinugawa T, Ogino K, et al. Augmented response in plasma brain natriuretic peptide to dynamic exercise in patients with left ventricular dysfunction and congestive heart failure. J Intern Med 2000; 248:309-315. 
198. Engelmann M, Nieman L, Kanstrup I, Skagen K, Godtfredsen J. Natriuretic peptide response to dynamic exercise in patients with atrial fibrillation. Int J Cardiol 2005; 105:31-39.

199. Tanaka M, Ishizaka Y, Ishiyama Y, et al. Exercise-induced secretion of brain natriuretic peptide in essential hypertension and normal subjects. Hypertens Res 1995; 18:159-166.

200. Haufe S, Kaminski J, Utz W, et al. Differential response of the natriuretic peptide system to weight loss and exercise in overweight or obese patients. J Hypertens 2015 ; 33:14581464.

201. Bordbar S, Bigi M, Aslani A, Rahimi E, Ahmadi N. Effect of endurance and strength exercise on release of brain natriuretic peptide. J Cardiovasc Dis Res 2012; 3:22-25.

202. Beltran Valls M, Dimauro I, Brunelli A, et al. Explosive type of moderate-resistance training induces functional, cardiovascular, and molecular adaptations in the elderly. Age 2014; 36:759-772.

203. Lu J, Pan S. Elevated C-type natriuretic peptide elicits exercise preconditioning-induced cardioprotection against myocardial injury probably via the up-regulation of NPR-B. $J$ Physiol Sci 2016 [Epub ahead of print]

204. Liu Y, Li J, Zhang Z, Tang Y, Chen Z, Wang Z. Effects of exercise intervention on vascular endothelium functions of patients with impaired glucose tolerance during prediabetes mellitus. Exp Ther Med 2013; 5:1559-1565.

205. Jenkins N, Padilla J, Rector R, Laughlin M. Influence of regular physical activity and caloric restriction on $\beta$-adrenergic and natriuretic peptide receptor expression in retroperitoneal adipose tissue of OLETF rats. Exp Physiol 2013; 98:1576-1584.

206. Moro C, Pasarica M, Elkind-Hirsch K, Redman L. Aerobic exercise training improves atrial natriuretic peptide and catecholamine-mediated lipolysis in obese women with polycystic ovary syndrome. J Clin Endocrinol Metab 2009; 94:2579-2586. 
207. Fenzl M, Schnizer W, Aebli N, et al. Release of ANP and fat oxidation in overweight persons during aerobic exercise in water. Int J Sports Med 2013; 34:795-799.

208. Menshikova E, Ritov V, Toledo F, Ferrell R, Goodpaster B, Kelley D. Effects of weight loss and physical activity on skeletal muscle mitochondrial function in obesity. Am $J$ Physiol Endocrinol Metab 2005; 288:E818-E825.

209. Li C, Yu Q, Yu P, Yu T, Zhang Q, Lu S, Yu D. Changes in liraglutide-induced body composition are related to modifications in plasma cardiac natriuretic peptides levels in obese type 2 diabetic patients. Cardiovasc Diabetol 2014; 13:36.

210. St Peter J, Hartley G, Murakami M, Apple F. B-type natriuretic peptide (BNP) and Nterminal pro-BNP in obese patients without heart failure: relationship to body mass index and gastric bypass surgery. Clin Chem 2006; 52:680-685.

211. Changchien E, Ahmed S, Betti F, Higa J, Kiely K, Hernandez-Boussard T, Morton J. Btype natriuretic peptide increases after gastric bypass surgery and correlates with weight loss. Surg Endosc 2011; 25:2338-2343.

212. Chainani-Wu N, Weidner G, Purnell D, et al. Relation of B-type natriuretic peptide levels to body mass index after comprehensive lifestyle changes. Am J Cardiol 2010; 105:1570-1576.

213. Chen-Tournoux A, Khan A, Baggish A, et al. Effect of weight loss after weight loss surgery on plasma N-terminal pro-B-type natriuretic peptide levels. Am J Cardiol 2010; 106:1450-1455.

214. Abrahamsson N, Engström B, Sundbom M, Karlsson F. Gastric bypass surgery elevates NT-ProBNP levels. Obes Surg 2013; 23:1421-1426.

215. Kistorp C, Bliddal H, Goetze J, Christensen R, Faber J. Cardiac natriuretic peptides in plasma increase after dietary induced weight loss in obesity. BMC Obes 2014; 1:24 
216. Hanusch-Enserer U, Hermann K, Cauza E, et al. Effect of gastric banding on aminoterminal pro-brain natriuretic peptide in the morbidly obese. Obes Res 2003; 11:695-698.

217. Minami J, Nishikimi T, Ishimitsu T, et al. Effect of a hypocaloric diet on adrenomedullin and natriuretic peptides in obese patients with essential hypertension. J Cardiovasc Pharmacol 2000; 36:S83-S86.

218. Gabrielsen A, Omland T, Brokner M, et al. The effect of surgical and non-surgical weight loss on $\mathrm{N}$-terminal pro-B-type natriuretic peptide and its relation to obstructive sleep apnea and pulmonary function. BMC Res Notes 2016; 9:440.

219. Ichiki T, Burnett J. Atrial natriuretic peptide - old but new therapeutic in cardiovascular disease. Circ J 2017; 81:913-919.

220. Asakura M, Jiyoong K, Minamino T, et al. Rationale and design of a large-scale trial using atrial natriuretic peptide (ANP) as an adjunct to percutaneous coronary intervention for ST-segment elevation acute myocardial infarction: Japan-Working groups of acute myocardial infarction for the reduction of Necrotic Damage by ANP (J-WIND-ANP). Circ J 2004; 68:95-100.

221. O’Connor C, Starling R, Hernandez A, et al. Effect of nesiritide in patients with acute decompensated heart failure. N Engl J Med 2011; 365:32-43.

222. Suwa M, Seino Y, Nomachi Y, et al. Multicenter prospective investigation on efficacy and safety of carperitide for acute heart failure in the 'real world' of therapy. Circ J 2005; 69:283-290. 